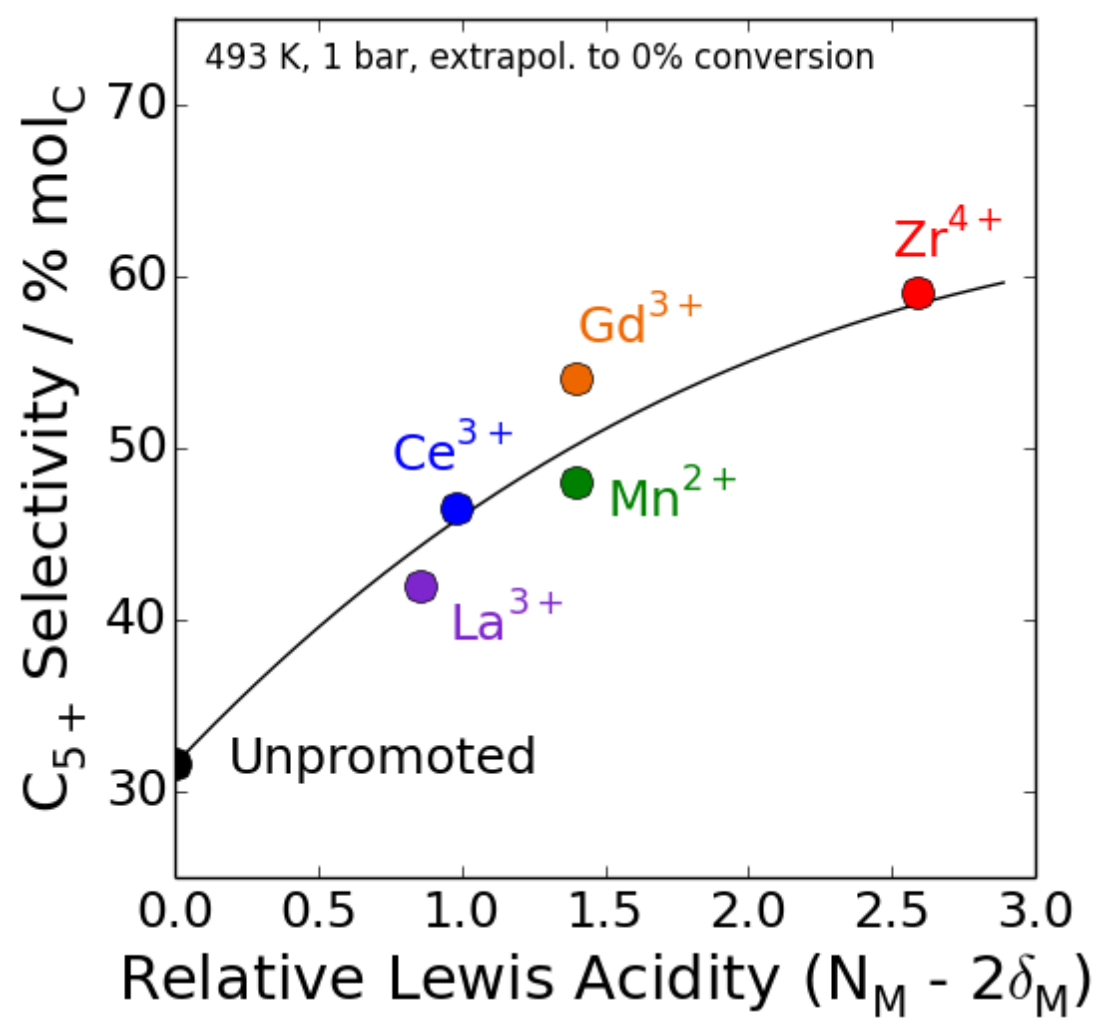




\title{
Effects of Lewis Acidity of Metal Oxide Promoters on the Activity and Selectivity of Co-Based Fischer-Tropsch Synthesis Catalysts
}

\author{
Gregory R. Johnson ${ }^{a}$, Alexis T. Bell ${ }^{a, b, *}$ \\ ${ }^{a}$ Department of Chemical and Biomolecular Engineering, University of California, Berkeley, \\ California 94720, United States \\ ${ }^{b}$ Chemical Sciences Division, Lawrence Berkeley National Laboratory, Berkeley, California \\ 94720, United States
}

Submitted to

Journal of Catalysis

March 18, 2016

*corresponding author: bell@cchem.berkeley.edu 


\begin{abstract}
Metal oxides of $\mathrm{Ce}, \mathrm{Gd}, \mathrm{La}, \mathrm{Mn}$, and $\mathrm{Zr}$ were investigated as promoters for improving the activity and selectivity of Co-based FTS catalysts. The extent to which these promoters decrease the selectivity toward $\mathrm{CH}_{4}$ and increase the selectivity toward $\mathrm{C}_{5+}$ hydrocarbons was found to depend on both the loading and the composition of the oxide promoter. Elemental mapping by STEM-EDS revealed that the propensity for a given metal oxide to associate with Co affects the sensitivity of the product distribution to changes in promoter loading. For all promoters, a sufficiently high loading resulted in the product distributions becoming insensitive to further increases in promoter loading, very likely due to the formation of a half monolayer of promoter oxide over the Co surface. Simulations suggest that the fraction of Co active sites that are adjacent to the promoter moieties approaches unity at this degree of coverage. The oxidation state of the promoter metal cation under reaction conditions, determined by in situ XANES measurements, was used to calculate relative Lewis acidity of the promoter metal cation. A strong positive correlation was found between the $C_{5+}$ product selectivity and the Lewis acidity of the promoter metal cations, suggesting that the promotional effects are a consequence of Lewis acid-base interactions between the reaction intermediates and the promoter metal cations. Rate data obtained at different pressures were used to estimate the apparent rate coefficient and the CO adsorption constant appearing in the Langmuir-Hinshelwood expression that describes the CO consumption kinetics for both unpromoted and the metal oxide-promoted catalysts. Both parameters exhibited positive correlations with the promoter Lewis acidity. These results are consistent with the hypothesis that the metal cations of the promoter act as Lewis acids that interact with the $\mathrm{O}$ atom of adsorbed CO to facilitate $\mathrm{CO}$ adsorption and dissociation.
\end{abstract}

\title{
Keywords
}

Fischer-Tropsch Synthesis, Heterogeneous Catalysis, Cobalt, Promotion, Lewis Acidity 


\section{Introduction}

Fischer-Tropsch synthesis (FTS) over Co-based catalysts offers a means for converting synthesis gas, a mixture of $\mathrm{CO}$ and $\mathrm{H}_{2}$ produced from gasification of biomass, coal, and natural gas, to transportation fuels. Since the products of FTS over metallic Co contain a significant portion of $\mathrm{CH}_{4}$ and light alkanes and alkenes, considerable effort has been devoted toward identifying and optimizing promoters that reduce the formation of light hydrocarbons and enhance the formation of C5+ hydrocarbons, since the latter products can be used to produce transportation fuels (1). It has been demonstrated that the desired goal can be met using metal oxide promoters (2) (3). For example, work by de Jong et al. (4) (5) and Weckhuysen et al. (6) (7) (8) (9) (10) has reported that promotion with MnO enhances the rate of $\mathrm{CO}$ consumption and $\mathrm{C}_{5+}$ selectivity. Studies by these authors and others have shown that these effects are a consequence of good contact between metallic Co and MnO (11) (12). Similar findings have also been reported for $\mathrm{ZrO}_{2}$ (13) (14) (15) (16) and for oxides of Ce (17) (18), Gd (19), La (20) (21) (22) (23), Mo (24) (25), and Ti (26) (27) (28). However, despite the abundance work on metal oxide promotion, there have not been extensive efforts to compare promoter elements directly and rationalize any differences in terms of periodic trends.

It has been reported that the electronic and catalytic properties of metal sites located at the interface between metal nanoparticles and an oxide support may differ from those of sites located farther from the oxide support due to the local transfer of charge between metal atoms of the nanoparticle and the oxide in the region of the metal-metal oxide interface (29) (30). A similar effect has also been proposed for metal sites located at the interface between a metal oxide promoter and a metal nanoparticle. For example, the rate of CO methanation over Pd has been observed to be enhanced when the catalyst is promoted with $\mathrm{La}_{2} \mathrm{O}_{3}$ moieties (31). Similarly, the rate of $\mathrm{CO}$ hydrogenation over $\mathrm{Rh}$ has been found to increase when Rh nanoparticles are partially covered by metal oxides (32) (33). These findings have led to the hypothesis that sites located at the metal-metal oxide interface in Co-based FTS catalysts facilitate cleavage of the $\mathrm{C}-\mathrm{O}$ bond, a necessary step in the hydrogenation of $\mathrm{CO}$ to hydrocarbons (34). Specifically, it has been proposed that metal cations of the promoter located at the metal-metal oxide interface act as Lewis acids that interact with the $\mathrm{O}$ atom of $\mathrm{CO}$ bound through the $\mathrm{C}$ atom to the metal nanoparticle, thereby weakening the $\mathrm{C}-\mathrm{O}$ bond and facilitating its dissociation either directly or following partial hydrogenation (35). This reasoning suggests that the magnitude of metal oxide-based promotional effects should be related to the Lewis acidity of the promoter. Recently, we have reported the existence of correlations between the $\mathrm{C}_{5+}$ selectivity of Co-based FTS catalysts and the 
Lewis acidity of promoter metal cations (36) (37). This line of reasoning is also supported by the work of Prieto et al., who have reported a relationship between both the FTS turnover frequency and $\mathrm{C}_{13+}$ selectivity and the Lewis acidity of oxide supports (38). These cited results identify the role of Lewis acidity in understanding promotional effects, but the importance of interface formation between the Co and the metal oxide promoter and the effects of Lewis acidity on the rate law parameters have not been clearly defined yet.

The aim of the present study was to compare and contrast the effects of metal oxide promoters $\left(\mathrm{CeO}_{x}, \mathrm{GdO}_{x}, \mathrm{LaO}_{x}, \mathrm{MnO}_{x}\right.$, and $\left.\mathrm{ZrO}_{\mathrm{x}}\right)$ on the catalytic properties of Co-based FTS catalysts. Of particular interest were the extent to which each of these oxides associates with Co and the dependence of promotion effects on promoter composition. $\mathrm{Co} / \mathrm{SiO}_{2}$ promoted with increasing levels of the metal oxide promoter were prepared and their performance was investigated at various temperatures, pressures, and space velocities. The distribution of the oxide on the support and the degree of contact between the oxide and the dispersed Co nanoparticles were determined from STEM-EDS elemental maps. These measurements revealed that the degree of Co-promoter interaction is a strong function of the metal oxide composition and loading. Recognizing this, efforts were undertaken to determine the effects of promoter composition on the rate parameters governing the rate of $\mathrm{CO}$ consumption using catalysts with nearly equivalent levels of contact between the metallic Co and the promoter. This work strongly suggests that the formation of an interface between the Co and the promoter oxide is responsible for the promotional effects. The active sites in the promoted catalysts are presumed to occur at the metalmetal oxide interface, and evidence is found that such sites enhance CO adsorption and dissociation of the $\mathrm{C}-\mathrm{O}$ bond. Moreover, the strength of these promotional effects is found to correlate with the Lewis acidity of the promoter, supporting the hypothesis that Lewis acid-base interactions are responsible for metal oxide promotion of FTS on Co.

\section{Experimental Section}

\subsection{Catalyst Synthesis}

Catalysts were prepared following the procedures described previously (39). For the unpromoted catalyst, incipient wetness impregnation was used to deposit $\mathrm{Co}\left(\mathrm{NO}_{3}\right)_{2}$ (Sigma-Aldrich, 99.999\% purity) onto porous $\mathrm{SiO}_{2}$ (PQ Corporation, CS-2129). The promoted catalysts were prepared by co-impregnation with an aqueous solution of $\mathrm{Co}\left(\mathrm{NO}_{3}\right)_{2}$ and the precursor for the promoter element. For this work, the promoted catalysts were prepared using either $\mathrm{Mn}$ acetate or nitrate salts of $\mathrm{Ce}, \mathrm{Gd}, \mathrm{La}$, 
or $\mathrm{Zr}$ (Sigma-Aldrich, 99.999\% purity). $\mathrm{Mn}\left(\mathrm{CH}_{3} \mathrm{CO}_{2}\right)_{2}$ was used because this precursor has previously been shown to yield the desired catalyst structure (40). When using precursors with limited solubility, multiple impregnation steps were used to achieve the desired metal loadings. The solvent from the previous impregnation step was allowed to evaporate at ambient conditions prior to conducting the next impregnation step. After the metal precursors were deposited onto the $\mathrm{SiO}_{2}$, the sample was dried overnight at ambient temperature and then heated at $5 \mathrm{~K} / \mathrm{min}$ to $723 \mathrm{~K}$ under flowing $\mathrm{H}_{2}(100 \mathrm{~mL} / \mathrm{min})$ and held at $723 \mathrm{~K}$ for $2 \mathrm{~h}$. After this step, the reduced catalyst was cooled to ambient temperature under flowing $\mathrm{He}(100 \mathrm{~mL} / \mathrm{min})$. The catalyst was then exposed to $500 \mathrm{ppm} \mathrm{O}_{2}(100 \mathrm{~mL} / \mathrm{min})$ to passivate the Co.

\subsection{Temperature-Programmed Reduction}

The reduction profiles for the passivated catalysts were obtained by heating the samples from ambient temperature to $850 \mathrm{~K}$ at $5 \mathrm{~K} / \mathrm{min}$ in a quartz tube reactor under flowing $1 \% \mathrm{H}_{2}, 1 \% \mathrm{Ar}$, and $98 \%$ He $(30 \mathrm{~mL} / \mathrm{min})$. The composition of the reactor effluent was monitored by an MKS Minilab quadrupole mass spectrometer. Corrections for variations in the reactor effluent flow rate were made using the $\mathrm{Ar}$ signal as an internal standard.

\section{$2.3 \mathrm{O}_{2}$ Titration}

$\mathrm{O}_{2}$ titrations of the reduced catalysts were performed using a Micromeritics AutoChem II 2920 instrument. In a typical measurement, a sample of passivated catalyst was loaded into a quartz U-tube, which was then inserted into the instrument. The sample was reduced by heating it at $5 \mathrm{~K} / \mathrm{min}$ to $723 \mathrm{~K}$ under flowing $\mathrm{H}_{2}(100 \mathrm{~mL} / \mathrm{min})$ and then holding it at $723 \mathrm{~K}$ for $2 \mathrm{~h}$. The sample tube was subsequently flushed with $\mathrm{He}(100 \mathrm{~mL} / \mathrm{min})$ until the thermal conductivity detector (TCD) in the instrument achieved a stable baseline signal. Pulses of $20 \% \mathrm{O}_{2}$ in $\mathrm{He}(3.1 \mu \mathrm{mol} \mathrm{O} /$ pulse) were then injected into the He carrier gas flow every $6 \mathrm{~min}$ in order to titrate the reduced catalyst. The final $\mathrm{O}_{2}$ uptake was determined by the number of pulses required to achieve TCD peaks of equal area.

\section{4 $\mathrm{H}_{2}$ Chemisorption}

Static $\mathrm{H}_{2}$ chemisorption was performed using a Micromeritics 3Flex surface characterization analyzer. Passivated catalyst samples were loaded into a quartz $\mathrm{U}$-tube and then reduced by heating at 5 $\mathrm{K} / \mathrm{min}$ to $723 \mathrm{~K}$ under flowing $\mathrm{H}_{2}$ and holding at $723 \mathrm{~K}$ for $2 \mathrm{~h}$. The sample tube was then evacuated for 2 h at $723 \mathrm{~K}$ and cooled to $373 \mathrm{~K}$. An $\mathrm{H}_{2}$ adsorption isotherm was then collected by dosing a fixed quantity 
of $\mathrm{H}_{2}$ into the sample tube and allowing the pressure to equilibrate. Based on work by Reuel and Bartholomew (41), it was assumed that the total $\mathrm{H}_{2}$ uptake from a single isotherm collected at $373 \mathrm{~K}$ corresponds most closely to a $1 / 1 \mathrm{H} / \mathrm{Co}$ adsorption stoichiometry, neglecting any $\mathrm{H}_{2}$ spillover onto the promoter oxide. As described in the Results section, severe $\mathrm{H}_{2}$ spillover occurred on the lanthanidepromoted catalysts, which prevented the $\mathrm{H}_{2}$ uptake data from being used to determine the quantity of surface Co metal for these catalysts.

\subsection{X-Ray Absorption Spectroscopy}

X-ray absorption spectroscopy (XAS) measurements were conducted at beamlines 5-BM (DNDCAT) and 10-BM (MRCAT) (42) at the Advanced Photon Source synchrotron at Argonne National Laboratory. All spectra were acquired in transmission mode with the energy of the incident X-rays controlled by a Si(111) monochromator. The samples were placed between two gas ionization detectors to measure the absorption of X-rays, and a reference metal foil was placed between the second and a third detector to calibrate the X-ray energies and align the spectra. Catalyst samples were pressed into pellets and placed inside a cell that was heated by a tube furnace and connected to a gas inlet manifold. X-ray absorption near-edge structure (XANES) spectra of the passivated catalysts were collected at the Co K-edge and promoter $\mathrm{L}_{3}$-edge before reducing the catalysts by heating the cell at $5 \mathrm{~K} / \mathrm{min}$ to $723 \mathrm{~K}$ under flowing $\mathrm{H}_{2}$ and holding at $723 \mathrm{~K}$ for $2 \mathrm{~h}$. Following the reduction step, the catalysts were cooled to ambient temperature under flowing He and extended X-ray absorption fine structure (EXAFS) spectra were collected at the Co K-edge along with XANES spectra at the promoter $\mathrm{L}_{3}$-edge. The cell temperature was then increased to $493 \mathrm{~K}$ and the catalysts were exposed to a $2 / 1 \mathrm{H}_{2} / \mathrm{CO}$ synthesis gas mixture. After $6 \mathrm{~h}$ of aging under synthesis gas, a final set of XANES spectra were collected. The Demeter software family (43), which uses IFFEFIT internally (44), was used to process and analyze the XAS spectra. Fits of the EXAFS region of the spectra were done following the procedures described in our recent study of $\mathrm{ZrO}_{x}$-promoted catalysts (39).

\subsection{STEM Imaging and Elemental Mapping}

Samples for electron microscopy were prepared by drop-casting ethanol suspensions of ground catalyst particles onto lacey carbon-covered CU TEM grids (Ted Pella). The TEM grids were dried in a vacuum oven at $383 \mathrm{~K}$ for $1 \mathrm{~h}$ to evaporate the solvent. All microscopy work was conducted at the National Center for Electron Microscopy at the Molecular Foundry of the Lawrence Berkeley National Laboratory using an FEI Titan electron microscope that was operated with an accelerating voltage of 200 
kV. Co nanoparticle size distributions were obtained by high-angle, annual dark-field scanning transmission electron microscopy (HAADF-STEM). Energy dispersive spectroscopy (EDS) with a Bruker, four-segment, silicon drift detector was used to obtain elemental maps of the Co and promoter elements. For these measurements, the fluorescent X-ray spectrum from 0-20 keV was collected with an energy resolution of $140 \mathrm{eV}$ and a dispersion of $10 \mathrm{eV}$ per channel. The electron micrographs and elemental maps were analyzed by the ImageJ and Bruker Esprit software programs, respectively. Nanoparticle compositions were determined from the elemental map data by the Cliff-Lorimer method (45) using the Ce $\mathrm{L}_{\alpha}(4.839 \mathrm{keV}), \mathrm{Co} \mathrm{K}_{\alpha}(6.931 \mathrm{keV}), \mathrm{Gd} \mathrm{L}_{\alpha}(6.053 \mathrm{keV})$, and $\mathrm{La}_{\alpha}(4.647 \mathrm{keV}) \mathrm{X}$-ray peaks. Peak deconvolution was performed by the software to obtain accurate areas for the Co $K_{\alpha}$ and $G_{d} L_{\alpha}$ peaks, which were close in energy, and to remove $\mathrm{Fe}$ and $\mathrm{Cu}$ background signals. The mapped regions were estimated to be thin enough such that self-absorption and secondary X-ray fluorescence would be negligible.

\subsection{Catalyst Activity and Selectivity}

Measurements of catalyst activity and selectivity were made in packed-bed reactors. For these experiments, a sample of passivated catalyst diluted with calcined $\mathrm{SiO}_{2}$ was loaded into either a quartz or stainless steel reactor (1 cm inner diameter) for reactions for atmospheric and elevated pressure, respectively. The reactor was heated by a tube furnace, and mass flow controllers were used to regulate the flow of gases to the reactor. A diaphragm back-pressure regulator controlled the pressure within the stainless steel reactor. Immediately downstream of the reactors were sample collection vessels, heated to $403 \mathrm{~K}$, for collection of the liquid wax products. An Agilent 6890N gas chromatograph was used for online analysis of the gaseous products leaving the sample collection vessels. All tubing downstream of the sample collection vessels was maintained at $503 \mathrm{~K}$ to prevent product condensation.

In a typical experiment, the catalyst was first reduced by heating the reactor at $5 \mathrm{~K} / \mathrm{min}$ to $723 \mathrm{~K}$ under flowing $\mathrm{H}_{2}(100 \mathrm{~mL} / \mathrm{min})$ and holding it at $723 \mathrm{~K}$ for $2 \mathrm{~h}$. The reactor was then flushed with $\mathrm{He}$ and cooled to $493 \mathrm{~K}$, the temperature used for all FTS reactions in this study. Over the course of $10 \mathrm{~min}$, synthesis gas composed of $7 \% \mathrm{Ar}, 31 \% \mathrm{CO}$, and $62 \% \mathrm{H}_{2}$ was gradually introduced into the reactor while the He flow was gradually stopped to prevent runaway conditions. The catalyst was then aged for $12 \mathrm{~h}$ under differential conversion conditions, after which the catalyst activity was stable to within $10 \%$ for the duration of the experiments. Measurements were then conducted at different pressures and space velocities. The reactor and $\mathrm{SiO}_{2}$ support were found to have negligible background activity, and the system was determined to satisfy the Weiss-Prater criterion (46) so that transport limitations could be 
ruled out. The conversion and activity of the catalysts were calculated as previously reported (39). At atmospheric pressure, the sum of the C-containing products was used to calculate activity; at elevated pressure where liquid wax production can be significant, the CO consumption was used to determine activity. The product selectivities were calculated according to the methods used by Dinse et al. (47). On a molar carbon basis, $\mathrm{CO}_{2}$ and oxygenates were less than $1 \%$ of the product distribution.

\section{Results}

\subsection{Effects of Metal Oxide Promotion on Co Reduction}

Temperature-programmed reduction (TPR) profiles for the unpromoted and metal oxidepromoted catalysts are shown in Figure 1. For the unpromoted catalyst and the catalysts promoted with $\mathrm{Ce}, \mathrm{Gd}$, La, and Mn, a single Co reduction peak was observed between 555 and $585 \mathrm{~K}$. Previous studies of supported Co propose a two-step reduction consisting of $\mathrm{Co}_{3} \mathrm{O}_{4}$ reduction to $\mathrm{CoO}$ followed by $\mathrm{CoO}$ reduction to Co metal (48) (49); however, these two reduction events can occur with very little temperature separation as reported by Martínez et al. for reduction of $\mathrm{CoO}_{\mathrm{x}}$ supported on SBA-15 (50). Since the temperature for $\mathrm{CoO}_{x}$ reduction observed in the present study is close to that reported by Martínez et al. for the reduction of $\mathrm{CO}_{3} \mathrm{O}_{4}$ to $\mathrm{CoO}(560$ to $580 \mathrm{~K}$ ) and $\mathrm{CoO}$ to Co metal (580 to $610 \mathrm{~K}$ ) and since the catalyst is active for FTS after reduction as low as $673 \mathrm{~K}$, it is likely that the observed reduction peak consists of overlapping contributions from the reduction of $\mathrm{Co}_{3} \mathrm{O}_{4}$ to $\mathrm{CoO}$ and the reduction of $\mathrm{CoO}$ to Co metal. A second broad peak centered near $723 \mathrm{~K}$ appears in most of the TPR profiles, which may correspond to partial reduction of Co species associated with the support or promoter (51) (52). Increasing the reduction temperature from 673 to $723 \mathrm{~K}$ did not affect catalyst activity substantially. Even if this additional reduction event corresponds to further Co formation, it does not appear to result in the formation of additional catalytically active sites. The TPR profile for the $\mathrm{ZrO}_{\mathrm{x}}$-promoted catalyst was more complex, with reduction peaks appearing at 475 and $675 \mathrm{~K}$. Based on these temperatures, it is plausible to assign the first and second peaks to the reduction of $\mathrm{Co}_{3} \mathrm{O}_{4}$ to $\mathrm{CoO}$ and the reduction of $\mathrm{CoO}$ to Co metal, respectively; however, it is unclear why $\mathrm{Zr}$ alters the phase of the passivated Co and whether this initial phase incorporates $\mathrm{Zr}$. The area of the first peak is close to that of the second peak, which is consistent with the results from $\mathrm{O}_{2}$ titration indicating that the $\mathrm{Co}_{3} \mathrm{O}_{4}$ reduces to $\mathrm{CoO}$ and only about half of the $\mathrm{CoO}$ reduces further to Co metal.

Most of the promoter oxides did not undergo reduction during catalyst pretreatment, but both $\mathrm{CeO}_{\mathrm{x}}$ and $\mathrm{MnO}_{\mathrm{x}}$ exhibited signs of reduction. For the $\mathrm{Mn}$-containing catalyst, there is a shoulder in the 
TPR profile near $480 \mathrm{~K}$, which possibly corresponds to the reduction of $\mathrm{MnO}_{2}$ to $\mathrm{MnO}$. Although the temperature for this reduction step is substantially lower than that for the first reduction step for bulk $\mathrm{MnO}_{2}$ (53), in situ XANES measurements confirmed that the $\mathrm{Mn}$ in the passivated catalysts had an apparent oxidation state of $4+$, which decreased to $2+$ after reduction. Similar observations were made for the $\mathrm{CeO}_{x}$-promoted catalyst in which the oxidation state of Ce decreased from $4+$ to $3+$. The small peak at $690 \mathrm{~K}$ in the TPR profile possibly corresponds to this reduction step and is about $70 \mathrm{~K}$ above the reported temperature at which bulk $\mathrm{CeO}_{2}$ undergoes partial reduction (54). The TPR profile for the $\mathrm{GdO}_{\mathrm{x}}$-promoted catalyst contains a broad peak centered at $700 \mathrm{~K}$, but the persistence of $\mathrm{Gd}^{3+}$ after reduction suggests that this peak is not related to the reduction of $\mathrm{Gd}$. Documenting these oxidation state changes is important because these events lead to higher $\mathrm{O}_{2}$ titration uptakes, which need to be taken into account when calculating the extent of Co reduction.

$\mathrm{O}_{2}$ titration uptakes for the reduced catalysts are listed in Table 1. These values were used to determine the extents of Co reduction, given in Table 2. XANES measurements of the Co apparent oxidation states suggested that the reduced catalysts consisted of a mixture of Co metal and CoO. Based on phase diagrams for $\mathrm{Co}$ and $\mathrm{O}$, the $\mathrm{Co}$ metal and $\mathrm{CoO}$ were assumed to fully oxidize to $\mathrm{Co}_{3} \mathrm{O}_{4}$ during the $\mathrm{O}_{2}$ titration measurements (55). The contribution of the promoter oxidation state change to the $\mathrm{O}_{2}$ uptake was included in the calculation assuming that $\mathrm{Mn}$ oxidizes from $2+$ to $4+$ and that Ce oxidizes from $3+$ to $4+$, as indicated by XANES measurements. These assumptions appear in eq. 1 where $f_{\text {Co,metal }}$ is the fraction of Co in the metallic state after reduction, $U_{O_{2}}$ is the molar uptake of $\mathrm{O}_{2}, N_{C o}$ is the moles of Co, $N_{P}$ is the moles of promoter, and $\gamma$ is the stoichiometric factor for the oxidation of the promoter. There appears to be a weak relationship between the extent of Co reduction and the temperature of the main TPR reduction peak. The promoted catalysts exhibited increasing $\mathrm{CoO}_{x}$ reduction temperatures and decreasing extents of reduction in the order $\mathrm{Mn}<\mathrm{Gd}<\mathrm{Zr}$. $\mathrm{CeO}_{\mathrm{x}}$-promoted $\mathrm{Co}$ was unusual in that it had a lower temperature of Co reduction than the unpromoted catalyst and yet its extent of Co reduction was lower than that for the unpromoted catalyst. This suggests that a portion of the Co was associated with the promoter in an irreducible phase dispersed over the support.

$$
f_{\text {Co,metal }}=\frac{2 U_{O_{2}}-\left(\frac{4}{3}-1\right) N_{C o}-\gamma N_{P}}{N_{C o}}
$$

\subsection{Effects of Metal Oxide Promotion on Co Nanoparticle Size}

To make meaningful comparisons between the unpromoted and metal oxide-promoted catalysts, it is important to establish whether the addition of the promoters resulted in changes in the 
mean diameter of the Co nanoparticles. Nanoparticles with diameters less than 6 to $10 \mathrm{~nm}$ have been shown to have lower turnover frequencies and higher selectivities toward $\mathrm{CH}_{4}$ than larger particles (56) (57). Consequently, similarly sized Co nanoparticles must be present in the metal oxide-promoted catalysts to assume the absence of promoter-induced Co particle size effects on catalyst activity and selectivity. Based on our prior work with $\mathrm{MnO}_{x^{-}}$(40) and $\mathrm{ZrO}_{x^{-}}$-promoted (39) catalysts, for which the nanoparticle diameters were close to $10 \mathrm{~nm}$ and largely independent of promoter loading, all catalysts in the present study were prepared with the same Co weight loading with respect to the sum of Co and $\mathrm{SiO}_{2}$ and pretreated by directly reducing the catalyst precursors in $\mathrm{H}_{2}$. This strategy was found to yield similarly sized Co nanoparticles for the lanthanide promoters as shown in Table 1.

The surface mean diameters (58) reported in Table 1 were obtained by examining about 300 nanoparticles from different regions in the HAADF-STEM images of the catalysts. Since the visual contrast between the Co nanoparticles and the $\mathrm{SiO}_{2}$ was often poor, STEM-EDS elemental maps were used to confirm which features corresponded to Co nanoparticles as opposed to concentrated regions of $\mathrm{SiO}_{2}$. The green highlighting in the images shown in Figure $\mathrm{S} 1$ illustrates how the Co particles could be identified. The Co nanoparticles frequently appeared in clusters, which is particularly evident in Figures S1B and S1C. Accordingly, the diameters were extracted from the HAADF-STEM images, which had higher spatial resolution than the elemental maps. The diameters reported in Table 1 were corrected for the density difference between Co metal and $\mathrm{CoO}$ because Co within the passivated catalysts was predominantly in the form of $\mathrm{CoO}$ prior to reduction. These procedures resulted in estimates for the mean nanoparticle diameters of between 9 and $12 \mathrm{~nm}$, which means that the Co particle sizes lie outside the regime where size effects on catalyst activity and selectivity might occur. The standard deviations of the nanoparticle size distributions ranged from 2 to $4 \mathrm{~nm}$ and were also not affected by the promoter.

\subsection{Effects of Metal Oxide Promotion on Co Nanoparticle Structure}

No evidence was observed for the presence of mixed phases of Co and the promoter. The Co Kedge EXAFS spectra of the reduced catalysts shown in Figure 2 are consistent with each catalyst consisting of a mixture of Co metal (presumed to be in the hexagonal close-packed crystal structure) and CoO. To provide context for these results, the spectrum of Co metal exhibits a peak at $R=2.18 \AA$, corresponding to the first coordination shell of neighboring $\mathrm{Co}$ atoms. The spectrum of the $\mathrm{CoO}$ reference sample contains peaks $R=1.61$ and $2.61 \AA$ for Co-O and Co-Co scattering paths, respectively. The EXAFS spectrum of the unpromoted catalyst is composed of metallic Co peaks principally, although 
contributions from $\mathrm{CoO}$ are also visible. The ratio of the intensity of the $\mathrm{CoO}$ peaks to that of the metallic Co peak increased with the promoters in the order $\mathrm{La}<\mathrm{Ce}<\mathrm{Mn}$. This feature is also present in the peaks corresponding to the higher order coordination shells that were not fit (i.e., between $\mathrm{R}=3$ and $6 \AA$ ). Qualitatively, these results match the ordering for the extents of Co reduction (Table 2) in which the unpromoted catalyst had the highest extent of reduction followed by the $\mathrm{LaO}_{x^{-}}, \mathrm{CeO}_{x^{-}}$, and $\mathrm{MnO}_{\mathrm{x}}$-promoted catalysts in that order. Of the elements considered in this study, the $\mathrm{ZrO}_{\mathrm{x}}$-promoted catalyst had the lowest extent of Co reduction. The EXAFS spectrum of this catalyst, which was reported previously (39), contains the highest $\mathrm{CoO}$ peak intensities relative to the Co metal peak intensity. Owing to the proximity of the energies for the Co K-edge and $\mathrm{Gd} \mathrm{L}_{2}$-edge, it was not possible to analyze the EXAFS region of the XAS spectrum of the $\mathrm{GdO}_{\mathrm{x}}$-promoted catalyst.

Without signs for the formation of metallic alloys or mixed oxides composed of the Co and the promoters, it is reasonable to conclude that any promoter in contact with the Co decorates the surface of the Co nanoparticles. Coverage of the Co surface by the promoter oxide should result in the fraction of the nanoparticle surface that is accessible to chemisorption being smaller for the promoted catalysts compared to the unpromoted catalyst. This hypothesis was tested by means of $\mathrm{H}_{2}$ adsorption experiments. For the unpromoted catalyst, a close agreement was found between the nanoparticle dispersion determined by TEM, 8.3\%, and the dispersion determined by $\mathrm{H}_{2}$ uptake, $8.5 \%$. For the promoted catalysts, TEM particle sizes and $\mathrm{H}_{2}$ uptake data were used to estimate the fraction of the nanoparticle surface covered by the promoter according to the procedure reported previously (40). As shown in Table 2, the $\mathrm{MnO}_{x^{-}}$and $\mathrm{ZrO}_{x}$-promoted catalysts both had $\mathrm{H}_{2}$ uptakes equivalent to about half of the Co nanoparticle surface assuming 1/1 H/Co adsorption stoichiometry, suggesting that the promoter formed a half monolayer over the metallic Co. Ce and Gd promotion led to comparatively large $\mathrm{H}_{2}$ uptakes that exceeded the upper limit of surface Co determined by TEM particle sizes. These results are clear indicators for the occurrence of $\mathrm{H}_{2}$ spillover from the Co onto the promoter occurring for these catalysts. As a consequence, the fractional coverage of the Co surface by the promoter cannot be determined for these catalysts. It is less clear whether the $\mathrm{LaO}_{\mathrm{x}}$-promoted catalyst was also subject to $\mathrm{H}_{2}$ spillover since the calculated dispersion by $\mathrm{H}_{2}$ chemisorption for this sample was less than the dispersion determined by TEM. However, given the chemical similarity of La to other lanthanides, it would be reasonable to consider the estimated $10 \%$ promoter coverage of the $\mathrm{LaO}_{\mathrm{x}}$-promoted Co as being underestimated. 


\subsection{Promoter Oxidation States and Structure}

The oxidation states of the promoters under reaction conditions were determined by in situ XANES measurements. Figure 3 shows the promoter $\mathrm{L}_{3}$-edge XANES spectra of the lanthanide-promoted catalysts in the passivated state, after reduction, and after $6 \mathrm{~h}$ exposure to synthesis gas. In Figure 3A, the spectrum of the $\mathrm{La} / \mathrm{Co}=0.1$ catalyst is very similar to that of $\mathrm{La}_{2} \mathrm{O}_{3}$, suggesting that the apparent oxidation state of the La promoter was $3+$ and did not change during the pretreatment or FTS reaction. The spectrum of the passivated $\mathrm{CeO}_{x}$-promoted catalyst most closely resembles that of $\mathrm{CeO}_{2}$ (Figure 3B).

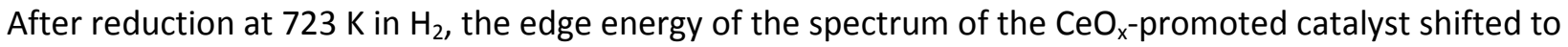
lower energy and resembled those of the $\mathrm{Ce}(\mathrm{III})$ references. Here, $\mathrm{Ce}\left(\mathrm{NO}_{3}\right)_{3}$ and $\mathrm{Ce}_{2}\left(\mathrm{SO}_{4}\right)_{3}$ were used as reference samples in place of $\mathrm{Ce}_{2} \mathrm{O}_{3}$ which oxidizes under ambient conditions. Exposing the reduced catalyst to FTS reaction conditions caused minimal changes in the spectrum. These results demonstrate that the apparent oxidation of $\mathrm{Ce}$ was $4+$ in the passivated state, underwent reduction to $3+$ following reduction in $\mathrm{H}_{2}$, and then remained at $3+$ under reaction conditions. The spectra of the $\mathrm{GdO}_{x}$-promoted catalyst were all similar to that for the $\mathrm{Gd}_{2} \mathrm{O}_{3}$ reference sample, indicating that Gd adopted a 3+ apparent oxidation state.

Although the metal oxidation states are essential for estimating Lewis acidities, the crystal structure and local environment of the promoter also need to be considered because they can affect the Lewis acidity of oxides (59). Owing to the highly dispersed nature of the promoters, it was not possible to identify their crystal structures by means of X-ray diffraction. Instead, XAS measurements were used to make inferences about the promoter coordination environments. Prior measurements of the $\mathrm{ZrO}_{x^{-}}$ promoted catalyst indicated that the promoter most closely resembled monoclinic $\mathrm{ZrO}_{2}$ at high loadings where the promotional effects were maximal (39). Additionally, it was determined that the promoter was highly dispersed over the catalyst surface. Similar findings were obtained for the $\mathrm{MnO}_{\mathrm{x}}$-promoted catalyst used in the present study. The positions of the first two peaks in the EXAFS spectrum of the reduced $\mathrm{MnO}_{\mathrm{x}}$-promoted catalyst closely match those for the $\mathrm{Mn}-\mathrm{O}$ and $\mathrm{Mn}-\mathrm{Mn}$ scattering paths in $\mathrm{MnO}$ with the rock-salt structure (Figure S2). A notable difference between the spectrum of the catalyst and that of $\mathrm{MnO}$ is the inversion in the relative intensities of these peaks. This is a consequence of the $\mathrm{Mn}$ being more highly dispersed within the catalyst such that a central $\mathrm{Mn}$ atom is surrounded by fewer neighboring $\mathrm{Mn}$ atoms than is the case for bulk $\mathrm{MnO}$. The high dispersion of the $\mathrm{Mn}$ promoter also contributes to the lower intensity of the EXAFS peaks between $R=3.3$ and $6 \AA$, resulting from nextnearest neighboring atoms located farther from the central absorbing atom. 
Unfortunately for the $\mathrm{Ce}, \mathrm{Gd}$, and La promoters, the $\mathrm{L}_{1^{-}}, \mathrm{L}_{2^{-}}$, and $\mathrm{L}_{3}$-edge EXAFS regions for each element overlap in energy, preventing analysis of the corresponding spectra. However, recent work by Asakura et al. has reported that a correlation exists between the full width at half maximum (FWHM) of the white line of the $\mathrm{La}_{3} \mathrm{~L}_{3}$-edge and the La coordination number (60). Following their procedure of fitting an arctangent and pseudo-Voigt function to the edge, it was determined that the widths of the $\mathrm{La}_{\mathrm{L}^{-}}$ edge white lines for the $\mathrm{L}_{2} \mathrm{O}_{3}$ reference and the $\mathrm{LaO}_{\mathrm{x}}$-promoted catalyst were similar $(4.7 \mathrm{eV})$, which suggests similar coordination environments for the La atoms in both samples. Based on these trends, it was assumed that the Ce and Gd promoters adopted crystal structures consistent with their bulk oxides.

\subsection{Spatial Association between Co and the Metal Oxide Promoters}

The ability of the lanthanide promoters to associate with Co was evaluated by elemental mapping. Representative STEM-EDS maps of these catalysts prepared with promoter loadings high enough that the product selectivity was insensitive to promoter loading are shown in Figure 4. Visual inspection of these maps reveals that different promoters exhibited different degrees of association with the $\mathrm{Co}$. For the $\mathrm{LaO}_{\mathrm{x}}$-promoted catalyst prepared with a La/Co atomic ratio of 0.1 (Figure 4A), a high degree of spatial overlap is observed between the La and Co channels (red and green, respectively). Here, yellow nanoparticles are clearly visible, which indicates the presence of both elements at the nanoparticle locations. The relatively low intensity of the La signal over the catalyst support indicates that most of the La was associated with the Co nanoparticles. By contrast, an absence of preferential association between the promoter and $\mathrm{Co}$ occurred for the $\mathrm{CeO}_{\mathrm{x}}$-promoted catalyst. Figure $4 \mathrm{~B}$ shows an extreme example for the catalyst prepared with $\mathrm{Ce} / \mathrm{Co}=2.0$ in which segregation is clearly visible between $\mathrm{Co}$ nanoparticles and $\mathrm{CeO}_{2}$. Although not all elemental maps of the $\mathrm{CeO}_{x}$-promoted catalyst exhibited such segregation, $\mathrm{CeO}_{2}$ was always found to be highly dispersed over the catalyst surface. The $\mathrm{GdO}_{\mathrm{x}}$-promoted catalyst prepared with a $\mathrm{Gd} / \mathrm{Co}$ ratio of 1.0 also appeared to lack a preferential association with Co, as can be seen in Figure $4 \mathrm{C}$ which shows that $\mathrm{Gd}$ is highly dispersed over the catalyst surface. For all catalysts, the promoter appears to be well dispersed over the support, and no features attributable to promoter oxide nanoparticles larger than nanometer scale were observed.

The elemental maps in Figure 4 suggest that $\mathrm{LaO}_{x}$ has a much stronger affinity for $\mathrm{Co}$ than $\mathrm{CeO}_{\mathrm{x}}$ and $\mathrm{GdO}_{\mathrm{x}}$. This conclusion is reinforced by the analysis of nanoparticle compositions in the promoted catalysts. Figure 5 shows nanoparticle composition histograms for the $\mathrm{CeO}_{x^{-}}, \mathrm{GdO}_{x^{-}}$, and $\mathrm{LaO}_{x^{-}}-$promoted catalysts at low and high promoter loadings. These data were obtained from the elemental maps by combining the X-ray spectra from all pixels within $1 \mathrm{~nm}$ of a nanoparticle and calculating the 
composition of this region using the Cliff-Lorimer method. Between 100 and 200 nanoparticles were quantified for a given catalyst sample to obtain a composition histogram. A summary of the means and standard deviations of the nanoparticle compositions distributions for each promoter, including $\mathrm{Mn}$ and $\mathrm{Zr}$, at low and high loadings is presented in Table S1.

In accordance with Figure 4A, the nanoparticle composition distribution for the catalyst prepared with La/Co $=0.1$ (Figure $5 \mathrm{~A}$ ) had a mean value of 0.094 , which is very close to the bulk La/Co ratio. By a material balance, this agreement between the mean nanoparticle composition and the bulk composition suggests that nearly all La was associated with the Co. The mean nanoparticle compositions for the $\mathrm{CeO}_{x^{-}}$and $\mathrm{GdO}_{x}$-promoted catalysts at the same loading were only 0.027 and 0.052 , respectively. These values are significantly lower than the total promoter/Co ratio of 0.1 , indicating that a substantial fraction of the promoter was not associated with the Co nanoparticles for both catalysts. Interestingly, the histograms for the $\mathrm{LaO}_{\mathrm{x}^{-}}$(Figure 5A) and $\mathrm{GdO}_{\mathrm{x}}$-promoted (Figure 5E) catalysts were modeled accurately by Gaussian functions whereas the composition distribution for the $\mathrm{CeO}_{\mathrm{x}}$-promoted (Figure 5C) catalyst had a shape that was closer to an exponential distribution. This difference may be a consequence of the Ce spatial distribution being negatively correlated with the Co. At higher loadings, the mean nanoparticle compositions for all the lanthanide-promoted catalysts were substantially lower than the catalyst bulk compositions (Figures 5B, 5D, and 5F). This is evidence that La in excess of an amount required to fully cover the surface of the Co deposits onto the support. A similar pattern was observed for the catalysts promoted by Ce and Gd.

Elemental maps and nanoparticle histograms for the $\mathrm{MnO}_{x^{-}}$and $\mathrm{ZrO}_{x}$-promoted catalysts were reported in our previous studies (40) (39). Briefly, the Mn exhibited a strong preference for associating with the $\mathrm{Co}$ at loadings below $\mathrm{Mn} / \mathrm{Co}=0.1$. At $\mathrm{Mn} / \mathrm{Co}=0.5$, the mean nanoparticle composition was 0.38, indicating that the additional $\mathrm{Mn}$ was dispersed over the support more so than on the Co nanoparticles. The location of the $\mathrm{Zr}$ did not appear to be correlated with the Co nanoparticles at low and high loadings, and the mean nanoparticle compositions for the $\mathrm{ZrO}_{\mathrm{x}}$-promoted catalysts were similar to those of the $\mathrm{GdO}_{x}$-promoted catalysts prepared with the same promoter/Co atomic ratios.

\subsection{Catalyst Activity and Selectivity}

For catalysts in which the surface of the active phase is partially covered by another material, it is important to compare catalytic activity on the basis of turnover frequencies. For Co-based FTS catalysts this is typically done by considering the number of $\mathrm{Co}$ atoms accessible to $\mathrm{H}_{2}$ chemisorption. 
While this technique has proven adequate for quantifying the surface Co atoms in unpromoted systems (61), the presence of a metal oxide promoter in contact with the Co surface may complicate the analysis. In the present study, there is strong evidence that $\mathrm{H}_{2}$ spillover occurred onto the lanthanide oxides, making it impossible to quantify the number of surface Co atoms. Therefore, using the $\mathrm{H}_{2}$ uptake data to compute the turnover frequencies may grossly underestimate the values for the catalysts on which heavy spillover occurred. Based on our prior studies of $\mathrm{MnO}_{x^{-}}$and $\mathrm{ZrO}_{x^{-}}$-promoted $\mathrm{Co} / \mathrm{SiO}_{2}$, for which $\mathrm{H}_{2}$ spillover did not appear to have a large contribution, we propose the following workaround. Together, $\mathrm{H}_{2}$ chemisorption uptakes and TEM particle size analysis suggest that $\mathrm{Mn}$ promotion effects are maximized when the $\mathrm{Mn}$ covers half the Co surface (40). These results were also found to apply for $\mathrm{Zr}$ promotion (39). Although these conclusions are empirically based, they are also consistent with theoretical expectations based on the simulated deposition of particles onto a surface (62). Assuming that the particles decorating the surface are randomly deposited, the number of surface sites adjacent to, but not covered by, the particles would be maximized when the surface is half-covered by the particles (see Figure S4). Accordingly, if active sites at the interface between the Co and the promoter are responsible for the promotion effects, it is reasonable to hypothesize that for the lanthanide promoters, the loading at which the full effects of the promoter are achieved should occur when a half monolayer of the promoter is established on the Co surface.

Using the assumption that at the optimal promoter loading, the Co surface was half covered by the promoter oxide, the CO consumption rates were normalized to obtain estimated turnover frequencies. Figure 6 shows the dependence of turnover frequency on reactor pressure at $493 \mathrm{~K}$ in the regime of differential CO conversion. For all catalysts, the turnover frequencies increased with pressure, which is an expected consequence of increasing surface intermediate concentrations. However, as the pressure increased, the turnover frequencies also became less sensitive to pressure, as a consequence of $\mathrm{CO}$ inhibition due to increasing $\mathrm{CO}$ surface coverage (47). The turnover frequencies for the $\mathrm{GdO}_{x^{-}}$, $\mathrm{MnO}_{x^{-}}$, and $\mathrm{ZrO}_{x^{-}}$-promoted catalysts were about twice as high as those for the unpromoted catalyst and the $\mathrm{CeO}_{x^{-}}$and $\mathrm{LaO}_{x}$-promoted catalysts. As a comparison, the turnover frequencies based on total $\mathrm{H}_{2}$ uptake are shown in Figure S3. In this figure, the turnover frequencies for the lanthanide oxidepromoted catalysts are substantially lower than even the unpromoted catalyst as a consequence of $\mathrm{H}_{2}$ spillover inflating the estimated number of active sites for the promoted catalysts.

To understand the effects of the promoters on CO adsorption and dissociation under FTS, a model was fit to the rate data using nonlinear least-squares regression. We have shown previously that 
a two-parameter Langmuir-Hinshelwood expression (eq. 2) describes the the CO consumption rates for the unpromoted, $\mathrm{MnO}_{x}$-promoted, and $\mathrm{ZrO}_{x}$-promoted catalysts (40) (39). In this expression, $-r_{C O}$ is the rate of CO consumption, $P_{\mathrm{H}_{2}}$ is the partial pressure of $\mathrm{H}_{2}$, and $P_{\mathrm{CO}}$ is the partial pressure of $\mathrm{CO}$. While this rate law was originally derived empirically (63), the equation can also be derived assuming $\mathrm{H}$ assisted CO dissociation as the rate determining step (64). Using this mechanism, the parameters $a$ and $b$ in the rate law correspond to the apparent rate coefficient for $\mathrm{CO}$ consumption and the $\mathrm{CO}$ adsorption constant, respectively. In the present work, it was assumed that this rate law also applies to the lanthanide oxide-promoted catalysts.

$$
-r_{C O}=\frac{a b P_{H_{2}} P_{C O}}{\left(1+b P_{C O}\right)^{2}}
$$

The fits to the rate data, represented by the curves through the turnover frequency data points in Figure 6, accurately described the dependence of the turnover frequencies for $\mathrm{CO}$ consumption on total pressure. A parity plot for all catalysts (Figure S5) is highly linear, confirming that the chosen rate law is suitable for describing the reaction kinetics. Values for the parameters $a$ and $b$ for each catalyst are given in Table 3. Both the apparent rate coefficient and the $\mathrm{CO}$ adsorption constant are larger for the metal oxide-promoted catalysts compared to the unpromoted catalyst. These results are consistent with the presence of the promoter facilitating $\mathrm{C}-\mathrm{O}$ bond cleavage and higher $\mathrm{CO}$ surface coverages. Although the estimates for the apparent rate coefficients depend on the total number of catalytically active sites, the $\mathrm{CO}$ adsorption constants were not affected by the site count. Consequently, the assumption of half monolayer coverage of the Co surface did not influence the fitting of the $\mathrm{CO}$ adsorption constants.

As shown in Figure 7, the selectivities to $\mathrm{CH}_{4}$ and $\mathrm{C}_{5+}$ decreased and increased, respectively, for all promoted catalysts as the promoter loading increased. At a high enough loading, the selectivities plateaued and became insensitive to further increases in the promoter/Co ratio. The onset of the plateau occurred at different promoter/Co ratios for different elements, and the maximal improvement in the product distribution achieved at high promoter loading varied depending on the promoter element. Both La and $\mathrm{Mn}$ promotion caused rapid onsets of the promotional effects with $\mathrm{CH}_{4}$ selectivity sharply decreasing and $\mathrm{C}_{5+}$ selectivity sharply increasing for these catalysts in the regime where the promoter/Co ratio was less than 0.1 . By contrast, the product selectivities changed gradually with promoter loading for the catalysts promoted with $\mathrm{Ce}, \mathrm{Gd}$, and $\mathrm{Zr}$. Only at a promoter/Co ratio of 1.0 for the $\mathrm{GdO}_{\mathrm{x}}$-promoted and $\mathrm{ZrO}_{\mathrm{x}}$-promoted catalysts and 2.0 for the $\mathrm{CeO}_{\mathrm{x}}$-promoted catalyst did the selectivities cease to depend on promoter loading. These different sensitivities of selectivity toward the 
promoter loading were not related to the maximal selectivity improvements that could be achieved with each promoter element. In ascending order, the $C_{5+}$ selectivities of the optimally-loaded catalysts increased with the promoter element as follows: $\mathrm{La}<\mathrm{Ce}, \mathrm{Mn}<\mathrm{Gd}<\mathrm{Zr}$. The selectivities toward $\mathrm{CH}_{4}$ and $\mathrm{C}_{2}-\mathrm{C}_{4}$ decreased with the identity of the promoter element in the same order.

At elevated pressure, the product distribution for all catalysts shifted toward higher molecular weight hydrocarbons, consistent with what has generally been observed for Co-based FTS catalysts (65). This is shown in Figure 8 for the $\mathrm{CH}_{4}$ and $\mathrm{C}_{5+}$ selectivities. While the ordinal ranking of the promoters with respect to selectivity was generally preserved as pressure increased, the product selectivities of the catalysts converged as pressure increased. Whereas the $\mathrm{C}_{5+}$ selectivity for the $\mathrm{ZrO}_{\mathrm{x}}$-promoted catalyst was $95 \%$ larger than that for the unpromoted catalyst at atmospheric pressure, there was only a $13 \%$ improvement in the $\mathrm{C}_{5+}$ selectivity with $\mathrm{Zr}$ promotion at 10 bar. The carbon number selectivities for the lanthanide-promoted catalysts were not dependent on CO conversion at atmospheric pressure; however, at pressures above 5 bar, the $\mathrm{CH}_{4}$ selectivity decreased and the $\mathrm{C}_{5+}$ selectivity increased slightly as $\mathrm{CO}$ conversion increased. Both of these phenomena were observed for the $\mathrm{MnO}_{\mathrm{x}^{-}}(40)$ and $\mathrm{ZrO}_{\mathrm{x}^{-}}$ promoted (39) catalysts.

\section{Discussion}

\subsection{Lewis Acidity of the Promoter Oxides}

Several approaches exist for quantifying the Lewis acidity of metal oxides. At the simplest level, the oxidation state-adjusted Pauling electronegativity of the metal cation can be used as a proxy for Lewis acidity. This was the approach taken by Boffa et al. in their work relating the Lewis acidity of metal oxides deposited on $\mathrm{Rh}$ foil to $\mathrm{CO}$ and $\mathrm{CO}_{2}$ hydrogenation rates (33). More commonly, the spectroscopic signatures of basic probe molecules, such as $\mathrm{CO}$ and pyridine, are used as qualitative metrics for the Lewis acidity of surfaces (66). Recent work by Jeong et al. has sought to bridge these approaches by creating a quantitative Lewis acidity scale for metal oxides based on Sanderson electronegativities (67). The definition of relative Lewis acidity proposed by these researchers is given by eq. 3 in which $N_{M}$ is the oxidation state of the metal cation and $\delta_{M}$ is the Sanderson partial charge (68) of the metal cation. It was found that eq. 3 exhibits a strong linear correlation with the energy of the intramolecular charge transfer (IMCT) band of alizarin (1,2-dihydroxy-9,10-anthracenedione), a sensitive probe molecule that coordinates with the cations present on the surface of metal oxides. 


$$
\text { rel. Lewis acidity }=N_{M}-2 \delta_{M}
$$

This Lewis acidity scale proposed by Jeong et al. was chosen for comparing promoters in the present work because of its validation by probe molecule spectroscopy and its applicability to a wide range of metal oxides, including lanthanide oxides. The suitability of this scale for catalytic studies has been demonstrated recently by Prieto et al. in their studies of synthesis gas chemistry over Rh (69) and Co-Ru (38) catalysts. In these studies, the Lewis acidity of oxide monolayer supports was related to catalyst activity and selectivity using the scale developed by Jeong et al. The shifts in the IMCT bands of alizarin adsorbed onto the oxide monolayers measured by Prieto et al. followed the same order with respect to oxide adsorbent as that reported by Jeong et al. for adsorption onto bulk oxides. Given the apparent insensitivity of Lewis acidity toward oxide thickness and the evidence that the promoters had coordination environments similar to those of their bulk counterparts, it was assumed that this Lewis acidity scale would be appropriate for the metal oxides in the present work. The Lewis acidity of the unpromoted catalyst, which serves as the point of reference, is not clearly defined by the scale because the characteristic feature of this catalyst is the lack of a metal oxide overlayer. To make comparisons between this catalyst and the metal oxide promoted catalysts, it was assumed that the lack of a promoter would be equivalent to a promoter with an oxidation state and Sanderson partial charge of 0. Hence, the unpromoted catalyst was assigned a value of 0 on the relative Lewis acidity scale. A list of the relative Lewis acidity values for the catalyst promoters is provided in Table 3 and, with more detail, in Table S2.

\subsection{Dependence of Catalytic Properties on Promoter Loading}

Although higher loadings of the promoters were always associated with improvements in the product distributions, the sensitivity of these promotional effects to promoter loading for each element were markedly different. There appears to be no relationship between the promoter Lewis acidity or the maximal $\mathrm{C}_{5+}$ selectivity that can be achieved with a given element and the sensitivity of the product distribution toward the loading of that element. However, a strong connection exists between the promoter loading effects and the spatial association between the Co and the promoter. Analysis of the $\mathrm{LaO}_{\mathrm{x}^{-}}$and $\mathrm{MnO}_{\mathrm{x}^{-}}$-promoted $\mathrm{Co}$ nanoparticle compositions revealed that these promoters associate preferentially with the Co up to a loading corresponding to a promoter/Co atomic ratio of about 0.1 . The maximum $\mathrm{C}_{5+}$ selectivity for these promoters was also reached with a promoter/Co ratio of about 0.1 . As the promoter loading increases above this critical ratio, the product selectivity does not change, and deposition of the additional promoter occurs onto the catalyst support separate from the Co 
nanoparticles. The insensitivity of the product distribution toward promoter loading is not a simple consequence of the additional promoter not being near the Co. The mean nanoparticle promoter/Co ratio still increases with promoter loading when the loading exceeds the critical ratio. Hence, rationalizing these effects requires a subtler explanation.

For the $\mathrm{LaO}_{\mathrm{x}}$ - and $\mathrm{MnO}_{\mathrm{x}}$-promoted catalysts, the critical atomic ratio is close to the quantity of promoter that would be required to form a half monolayer of the promoter on the surface of the Co. With patches of metal oxide decorating the Co surface, metal-metal oxide interfaces will form between the Co and the promoter. This phenomenon results in two ensembles of Co active sites: those that are separate from the promoter interface and those that are adjacent to the interface. The overall product selectivity of a promoted catalyst should then be the average of the selectivities of these two ensembles weighted by the product of the site turnover frequencies and the number of sites in each ensemble. A catalyst in which all active sites are located at an interface with the promoter will exhibit the intrinsic selectivity of the promoted sites, whereas a promoted catalyst in which no Co is in contact with the promoter will perform the same as an unpromoted catalyst. Supposing that sites at the metal-metal oxide interface yield less $\mathrm{CH}_{4}$ and more $\mathrm{C}_{5+}$ than unpromoted sites, this model explains why the product selectivities improve with increasing promoter loading up to a critical loading at which few Co sites remain that are not adjacent to the promoter oxide overlayer. Increasing the promoter/Co ratio above the critical ratio will result in lower specific activity owing to the Co surface becoming covered by the promoter so as to decrease the total number of sites. This effect underlies the higher activity per gram Co for unpromoted $\mathrm{Co} / \mathrm{SiO}_{2}$ compared to that of metal oxide-promoted catalysts (Figure S6).

The findings of the present study on $\mathrm{LaO}_{x^{-}}$and $\mathrm{MnO}_{x^{-}}$promoted $\mathrm{Co}$ are consistent with those reported earlier. In their studies of $\mathrm{LaO}_{x}$-promoted catalysts, Haddad et al. also found that the chain propagation probability and $\mathrm{C}_{2+}$ selectivity reached their maximal values with a La/Co ratio of 0.1 (23) (70). Vada et al. concluded that for a catalyst prepared with La/Co $=0.1$, the Co nanoparticle surface was about $33 \%$ covered by the promoter, which is close to our expectation for a surface covered by approximately a half monolayer (21). The observation of a plateau in the product selectivity as a function of $\mathrm{Mn}$ loading found in the course of our study agrees well with what had been reported earlier for $\mathrm{MnO}_{\mathrm{x}}$-promoted catalysts by den Breejen et al. (5). Together, these results suggest that our observation of close spatial association between the Co and both the La and Mn may be related to intrinsic properties of these elements more than to our catalyst preparation method. Moreover, the appearance of a plateau in the product selectivity at high promoter loadings for multiple promoter 
elements is consistent with our proposal that the effects of the promoter are related to coverage of the Co nanoparticle surface by the promoter.

The hypothesis that promoted active sites occur at the metal-metal oxide interface is also consistent with the selectivity data and elemental maps for the $\mathrm{CeO}_{x^{-}}, \mathrm{GdO}_{x^{-}}$, and $\mathrm{ZrO}_{x^{-}}$-promoted catalysts. For these elements, a more gradual onset of the promotion effects occurs in response to increasing promoter loading. As reported previously, the critical $\mathrm{Zr} / \mathrm{Co}$ ratio of 1.0 corresponds to a loading that would form a half monolayer of $\mathrm{ZrO}_{2}$ over the entire catalyst surface, which is corroborated by $\mathrm{Co}$ nanoparticle sizes and $\mathrm{H}_{2}$ uptake data (39). Assuming that patches of metal oxide are randomly distributed over the Co surface, the interfacial perimeter between the Co and the oxides should be maximized when the oxide loading is equivalent to a half monolayer (62). Accordingly, it is reasonable to propose that the $\mathrm{Co}-\mathrm{ZrO}_{2}$ interface is maximized at $\mathrm{Zr} / \mathrm{Co}=1.0$ and the fraction of sites that are promoted is near unity, which results in the product selectivity not improving with higher Zr loadings. Similar to $\mathrm{ZrO}_{x}$, promotion with $\mathrm{GdO}_{x}$ showed no correlation with the locations of the Co nanoparticles, which explains why the critical $\mathrm{Gd} / \mathrm{Co}$ ratio was also 1.0. The larger critical ratio for $\mathrm{CeO}_{x}$ of 2.0 may be the result of a weak negative correlation between the $\mathrm{Ce}$ and $\mathrm{Co}$ spatial distributions. If $\mathrm{CeO}_{\mathrm{x}}$ has a preference for segregating from the Co, then a higher loading of the promoter would be required for the Co surface to become optimally saturated by the oxide.

The relationship between the promoter composition and the critical atomic ratio is likely related to the strength of the interactions between the promoter oxide with $\mathrm{Co}$ and $\mathrm{SiO}_{2}$. Expanding on this concept, the ability of Co to form mixed oxides with the promoter during the initial precursor decomposition and pretreatment steps may be important. MnO adopts a rock salt crystal structure similar to $\mathrm{CoO}$ and the formation of mixed oxides containing the two metals is well-known (71) (72). Although $\mathrm{Zr}$ has an ionic radius similar to that of $\mathrm{Co}, \mathrm{Zr}$ is tetravalent and $\mathrm{ZrO}_{2}$ adopts a monoclinic crystal structure. Mixed oxides of Co and Zr have been reported (73), but it is unclear whether these phases can undergo reduction so as to release Co so that it can form metal nanoparticles. Mixed oxides containing Co and either Ce (74), La (75), and Gd (76) have been reported, typically with perovskite crystal structures, but it is difficult to deduce from existing data why the La appears to associate so readily with the Co after reduction, whereas $\mathrm{Ce}$ and $\mathrm{Gd}$ have greater tendencies to segregate.

It is important to note that the preference of a given promoter element to associate with Co is not necessarily applicable to catalysts outside this study. The degree of element association depends heavily on the manner by which the catalysts are prepared. In contrast to the present work, Feltes et al. 
found that for $\mathrm{MnO}_{\mathrm{x}}$-promoted catalysts that supported on $\mathrm{TiO}_{2}$, the $\mathrm{C}_{5+}$ selectivity did not plateau below a $\mathrm{Mn} / \mathrm{Co}$ atomic ratio of at least 0.3 (11). Other researchers have found that $\mathrm{C}_{5+}$ selectivity can pass through a maximum at intermediate $\operatorname{Zr}(14)$ loadings. These examples illustrate the variability in catalytic properties resulting as a consequence of catalyst preparation method. Therefore, in order to compare the effects of different metal oxide promoters, it is important to monitor and control for variations in spatial association between the Co and the promoter.

\subsection{Influence of Promoter Lewis Acidity on Catalyst Activity and Selectivity}

In their studies of Rh-based catalysts, Sachtler et al. observed enhancements in the CO hydrogenation rate when metal oxides were added to the Rh surface (77). By analogy to coordination complexes in which carbonyls bond simultaneously to two metal atoms through both the $\mathrm{C}$ and $\mathrm{O}$ atoms (78), these researchers speculated that CO may adsorb onto Rh in a tilted configuration so as to interact with nearby metal oxides. These findings were extended by Boffa et al., who observed a positive correlation between both $\mathrm{CO}$ and $\mathrm{CO}_{2}$ hydrogenation rates and the Lewis acidity of metal oxide particles deposited onto Rh foil (33). Presumably, a stronger interaction between the $\mathrm{O}$ atom of adsorbed $\mathrm{CO}$ and the promoter results in a weaker $\mathrm{C}-\mathrm{O}$ bond that can be cleaved more readily. Similar mechanisms have been proposed for FTS over Co catalysts promoted with metal oxides (79). While there is ample evidence for improved FTS activity and selectivity in the presence of metal oxides (2), there have not been extensive efforts to conduct a controlled comparison of promoters from the perspective of Lewis acidity effects.

A key element of the hypothesis is that cations within the promoter oxides serve as Lewis acids and hence it would be expected that the magnitude of the promotional effects should scale with the Lewis acidity of the promoter. In addition to enhancing the rate of $\mathrm{CO}$ consumption through facilitated $\mathrm{CO}$ dissociation, it would be expected that the stronger binding of $\mathrm{CO}$ to the catalyst surface due to the presence of the promoter could decrease the ratio of $\mathrm{H} / \mathrm{CO}$ on the catalyst surface, thereby enhancing the formation of $\mathrm{C}_{5+}$ products and suppressing the formation of $\mathrm{CH}_{4}$. The FTS activity data reported here was examined for evidence of these effects, but a comparison between the FTS turnover frequencies with the promoter Lewis acidities did not reveal any clear trends. This is because promotion affects the rate law in a manner that creates both rate-enhancing and rate-inhibiting effects on the turnover frequencies. As shown in Figure 9, both the apparent rate coefficient for $\mathrm{CO}$ consumption and the $\mathrm{CO}$ adsorption constant correlate positively with promoter Lewis acidity. The correlation for the apparent rate coefficient is affected by the assumption that the Co nanoparticles are covered by a half monolayer 
of the promoter, but even if $\mathrm{H}_{2}$ uptakes are used as the basis for rate normalization, the correlation persists (Figure S7). The CO adsorption constant is not affected by the number of active sites, which may explain the greater linearity in the relationship between this parameter and the promoter Lewis acidity. Similar results are found for the relationship between product selectivity and promoter Lewis acidity. In Figure 10, the selectivities to $\mathrm{CH}_{4}, \mathrm{C}_{2}-\mathrm{C}_{4}$ hydrocarbons, and $\mathrm{C}_{5+}$ hydrocarbons are plotted as functions of promoter Lewis acidity. Here, a negative relationship is evident between the light hydrocarbon selectivity and the promoter Lewis acidity, and a positive correlation is observed for the formation of $\mathrm{C}_{5+}$ products.

Together, these correlations between both catalyst activity and selectivity and the promoter Lewis acidity support the interpretation that Lewis acid-base interactions occur between the promoter and the reaction intermediates on the Co surface. While the higher apparent rate coefficients for the promoted catalysts unambiguously contribute to higher activity, the effect of the higher CO adsorption constant is more complex. In the low pressure regime, the higher $\mathrm{CO}$ adsorption constant results in higher rates due to the increasing surface coverage of $\mathrm{CO}$; however, at high pressures where the surface is nearly saturated by $\mathrm{CO}$, the higher $\mathrm{CO}$ adsorption constant inhibits the reaction. Consequently, the turnover frequency for $\mathrm{CO}$ consumption is optimized with a promoter of intermediate Lewis acidity that balances the competing effects from the apparent rate coefficient and the CO adsorption constant. As shown in Figure $\mathrm{S} 8$, this optimum occurs with $\mathrm{Gd}_{2} \mathrm{O}_{3}$ and $\mathrm{MnO}$ when the reaction is conducted at $493 \mathrm{~K}$ and 10 bar. With respect to product selectivity, the best-performing promoter was $\mathrm{ZrO}_{2}$, which has the highest relative Lewis acidity of the oxides considered in this study. Since the selectivity improvements are largely attributed to the lower adsorbed H/CO ratio on the promoted catalyst surface (80) (47), it would be reasonable to predict that oxides with even higher relative Lewis acidities would result in yet higher $\mathrm{C}_{5+}$ selectivities.

It is important to compare the findings of the present study with those Prieto et al. who recently reported positive correlations between both turnover frequency and $\mathrm{C}_{13+}$ selectivity and the Lewis acidity of metal oxide supports (38). To a first approximation, the results of the present study are in agreement with those of Prieto et al.; however, there are two notable differences. First, the turnover frequencies reported by these authors increased monotonically with the relative Lewis acidity of the support, whereas in the present study an optimum at intermediate Lewis acidity was found. Although Prieto et al. controlled for nanoparticle size and pore size effects, the partial coverage of the Co nanoparticles by the metal oxide was not controlled, and catalysts prepared with $\mathrm{WO}_{\mathrm{x}}$ exhibited more 
surface decoration by the metal oxide than catalysts prepared with oxides of lower Lewis acidity. If sites at the metal-metal oxide interface are responsible for the enhancements in the turnover frequency, then the turnover frequency for the catalyst with the highest relative Lewis acidity in the study by Prieto et al. (i.e., the catalyst prepared with $\mathrm{WO}_{\mathrm{x}}$ ) could have been overestimated, which could account for the monotonic increase of the turnover frequency as a function of promoter Lewis acidity. However, we must concede that the assumption in the present study of half coverage of the Co surface by the promoter is imprecise and introduces uncertainty in our estimated turnover frequencies for the lanthanide-promoted catalysts.

The second difference between the two studies is that Prieto et al. observed the selectivity toward long-chain hydrocarbons to exhibit a maximum as a function of increasing promoter Lewis acidity, with the optimum selectivity being achieved with either $\mathrm{TiO}_{2}$ or $\mathrm{Ta}_{2} \mathrm{O}_{5}$. This is not experimentally inconsistent with the present study because we did not test elements with relative Lewis acidities greater than those for $\mathrm{TiO}_{2}$ and $\mathrm{Ta}_{2} \mathrm{O}_{5}$. However, this finding does not follow from the assumptions that the $\mathrm{CO}$ adsorption constant increases monotonically with higher promoter Lewis acidity and that the product distribution shifts to higher molecular weights due to decreases in the adsorbed $\mathrm{H} / \mathrm{CO}$ ratio resulting from the larger $\mathrm{CO}$ adsorption constant. A plausible explanation for the trend observed by Prieto et al. can be offered on the basis of electron withdrawal from the Co metal to the oxide support, an effect that is distinct from the proposed direct interaction between adsorbed CO and the promoter. Supports having stronger electronegativity have been found to decrease the electron density of Co nanoparticles more substantially than supports having weaker electronegativity (81). This effect results in adsorbed CO being less strongly bound to Co when the oxide support is more electronegative. Consequently, the oxide may contribute toward two opposing effects: strengthening of $\mathrm{CO}$ adsorption due direct interactions with adsorbed $\mathrm{CO}$ and weakening of $\mathrm{CO}$ adsorption due to electron withdrawal from the Co. To reconcile the findings of Prieto et al. with our own, we propose that for promoters with very high relative Lewis acidities, the effects of lower Co electron density may outcompete the direct interaction between the promoter and the adsorbed $\mathrm{CO}$ so as to result in a lower adsorbed $\mathrm{CO} / \mathrm{H}$ ratio on the Co surface. Hence, a promoter that is too Lewis acidic, specifically with a relative Lewis acidity higher than that of $\mathrm{ZrO}_{2}$, may be detrimental to achieving the desired product distribution. 


\section{Conclusions}

The promotion of Co-based FTS catalysts by metal oxides can result in improvements in both catalyst activity and selectivity, with the effectiveness of these promoters depending heavily on their composition and loading. For catalysts promoted with either $\mathrm{Ce}, \mathrm{Gd}, \mathrm{La}, \mathrm{Mn}$, or $\mathrm{Zr}$, the selectivity toward $\mathrm{CH}_{4}$ decreases and the selectivity toward $\mathrm{C}_{5+}$ increases as the promoter/Co ratio increases, but eventually a critical loading is reached above which the product selectivities are insensitive to further increases in the promoter loading. This phenomenon is attributed to the formation of a metal-metal oxide interface between the Co and the promoter. STEM-EDS imaging suggests that a connection exists between the critical loading and the degree of association between the Co and promoter. For elements that exhibit strong preferential association with Co, such as La and Mn, only a small amount of the promoter (promoter/Co $\approx 0.1$ ) is required to achieve the full promotional effects. Elements that appear to be dispersed over the catalyst support with no correlation with the Co nanoparticle locations, such as $\mathrm{Ce}, \mathrm{Gd}$, and $\mathrm{Zr}$, require promoter/Co ratios of at least unity before product selectivities become insensitive to promoter loading. Assuming that La and Mn promotion represent the extreme case of complete spatial association of the promoter with the $\mathrm{Co}$ and that $\mathrm{Ce}, \mathrm{Gd}$, and Zr promotion represent the counterpart where no spatial correlation exists, these different critical promoter/Co ratios all correspond to approximately half monolayer coverage of the Co nanoparticle surfaces. This finding is consistent with the hypothesis that active sites along the interface with the promoter oxide are responsible for the promotional effects.

Along with promoter loading, the identity of the promoter element exerts a significant effect on the magnitude of the promotional effects. For catalysts prepared with the critical promoter/Co ratios, $\mathrm{C}_{5+}$ hydrocarbon selectivity increases with the Lewis acidity of the promoter element. Although strongest at atmospheric pressure, this effect persists at pressures up to 10 bar. A strong positive correlation exists between the apparent rate coefficient for $\mathrm{CO}$ consumption and the promoter Lewis acidity, which implies that the promoter facilitates cleavage of the $\mathrm{C}-\mathrm{O}$ bond, most likely from adsorbed $\mathrm{CHOH}$. Relatedly, the CO adsorption constant correlates strongly with the promoter Lewis acidity, which suggests that the promoter increases the surface coverage of the catalyst by CO under reaction conditions. This increase in the extent of $\mathrm{CO}$ adsorption shifts the product distribution toward higher molecular weight hydrocarbons, but greater CO surface coverage also inhibits the reaction rate. This interplay between the rate enhancing effect of a higher apparent rate coefficient and the rate inhibiting 
effect of a higher $\mathrm{CO}$ adsorption constant results in the turnover frequency at 10 bar being optimized by promoters with an intermediate Lewis acidity, such as $\mathrm{Gd}_{2} \mathrm{O}_{3}$ or $\mathrm{MnO}$. The results presented in this study support the hypothesis that the role of the metal oxide promoter is to participate in Lewis acid-base interactions with adsorbed $\mathrm{CO}$. Furthermore, these findings establish a periodic trend that can be used to rationally select candidate promoter elements that have yet to be tested for their effects on catalyst performance.

\section{Acknowledgments}

The funding for this study was provided by the Director, Office of Science, Office of Basic Energy Sciences and by the Division of Chemical Sciences, Geosciences, and Biosciences of the U.S. Department of Energy at Lawrence Berkeley National Laboratory under Contract No. DE-AC02-05CH11231. Work at the Molecular Foundry was supported by the Office of Science, Office of Basic Energy Sciences, of the U.S. Department of Energy under Contract No. DE-AC02-05CH11231. This research used resources of the Advanced Photon Source, a U.S. Department of Energy (DOE) Office of Science User Facility operated for the DOE Office of Science by Argonne National Laboratory under Contract No. DE-AC02-06CH11357. Portions of this work were performed at the DuPont-Northwestern-Dow Collaborative Access Team (DND-CAT) located at Sector 5 of the Advanced Photon Source (APS). DND-CAT is supported by Northwestern University, E.I. DuPont de Nemours \& Co., and The Dow Chemical Company. MRCAT operations are supported by the Department of Energy and the MRCAT member institutions. We acknowledge assistance with the XAS measurements from Dr. Qing Ma, Dr. Konstantinos Goulas, Lin Louie, John Howell, Adam Grippo, and Julie Rorrer. 


\section{References}

1. Zhang, Q.; Kang, J.; Wang, Y. ChemCatChem 2010, 2, 1030-1058.

2. Khodakov, A. Y.; Chu, W.; Fongarland, P. Chem. Rev. 2007, 107, 1692-1744.

3. Oukaci, R.; Singleton, A. H.; Goodwin, J. G., Jr. Appl. Catal., A 1999, 186, 129-144.

4. Bezemer, G. L.; Radstake, P. B.; Falke, U.; Oosterbeek, H.; Kuipers, H. P. C. E.; van Dillen, A. J.; de Jong, K. P. J. Catal. 2006, 237, 152-161.

5. den Breejen, J. P.; Frey, A. M.; Yang, J.; Holmen, A.; van Schooneveld, M. M.; de Groot, F. M. F.; Stephan, O.; Bitter, J. H.; de Jong, K. P. Top. Catal. 2011, 54, 768-777.

6. Morales, F.; de Groot, F. M. F.; Glatzel, P.; Kleimenov, E.; Bluhm, H.; Hävecker, M.; KnopGericke, A.; Weckhuysen, B. M. J. Phys. Chem. B 2004, 108, 16201-16207.

7. Morales, F.; de Groot, F. M. F.; Gijzeman, O. L. J.; Mens, A.; Stephan, O.; Weckhuysen, B. M. J. Catal. 2005, 230, 301-308.

8. Morales, F.; Grandjean, D.; de Groot, F. M. F.; Stephan, O.; Weckhuysen, B. M. Phys. Chem. Chem. Phys. 2005, 7, 568-572.

9. Morales, F.; Grandjean, D.; Mens, A.; de Groot, F. M. F.; Weckhuysen, B. M. J. Phys. Chem. B 2006, 110, 8626-8639.

10. Morales, F.; de Smit, E.; de Groot, F. M. F.; Visser, T.; Weckhuysen, B. M. J. Catal. 2007, 246, 91-99.

11. Feltes, T. E.; Espinosa-Alonso, L.; de Smit, E.; D'Souza, L.; Meyer, R. J.; Weckhuysen, B. M.; Regalbuto, J. R. J. Catal. 2010, 270, 95-102.

12. Johnson, G. R.; Werner, S.; Bustillo, K. C.; Ercius, P.; Kisielowski, C.; Bell, A. T. J. Catal. 2015, $328,111-122$.

13. Ali, S.; Chen, B.; Goodwin, J. G., Jr. J. Catal. 1995, 157, 35-41.

14. Feller, A.; Claeys, M.; van Steen, E. J. Catal. 1999, 185, 120-130.

15. Moradi, G. R.; Basir, M. M.; Taeb, A.; Kiennemann, A. Catal. Commun. 2003, 4, 27-32.

16. Xiong, H.; Zhang, Y.; Liew, K.; Li, J. J. Mol. Catal. A: Chem. 2005, 231, 145-151.

17. Guerrero-Ruiz, A.; Sepúlveda-Escribaano, A.; Rodríguez-Ramos, I. Appl. Catal., A 1994, 120, 71-83.

18. Zeng, S.; Du, Y.; Su, H.; Zhang, Y. Catal. Commun. 2011, 13, 6-9.

19. Huber, G. W.; Butala, S. J. M.; Lee, M. L.; Bartholomew, C. H. Catal. Lett. 2001, 74, 45-48. 
20. Ledford J.S.; Houalla, M.; Proctor, A.; Hercules, D. M.; Petrakis, L. J. Phys. Chem. 1989, 93, 6770-6777.

21. Vada, S.; Kazi, A. M.; Bedu-Addo, F. K.; Chen, B.; Goodwin, J. G., Jr. La Promotion of Co Fischer-Tropsch Catalysts. In Natural Gas Conversion II; Curry-Hyde, H. E., Howe, R. F., Eds.; Elsevier Science: Amsterdam, The Netherlands, 1994; Vol. Studies in Surface Science and Catalysis 81, pp 443-448.

22. Adachi, M.; Yoshii, K.; Han, Y. Z.; Fujimoto, K. Bull. Chem. Soc. Jpn. 1996, 69, 1509-1516.

23. Haddad, G. J.; Chen, B.; Goodwin, J. G., Jr. J. Catal. 1996, 161, 274-281.

24. Cooper, C. G.; Nguyen, T.-H.; Lee, Y.-J.; Hardiman, K. M.; Safinski, T.; Lucien, F. P.; Adesina, A. A. Catal. Today 2008, 131, 255-261.

25. van Steen, E.; Vijoen, E. L.; van de Loosdrecht, J.; Claeys, M. Appl. Catal. A 2008, 335, 56-63.

26. Park, S. J.; Kim, S. M.; Woo, M. H.; Bae, J. W.; Jun, K. W.; Ha, K. S. Appl. Catal. A 2012, 419, 148-155.

27. Venezia, A. M.; La Parola, V.; Liotta, L. F.; Pantaleo, G.; Lualdi, M.; Boutonnet, M.; Jaras, S. Catal. Today 2012, 197, 18-23.

28. Wu, H. T.; Yang, Y.; Suo, H. Y.; Qing, M.; Yan, L.; Wu, B. S.; Xu, J.; Xiang, H. W.; Li, Y. W. J. Mol. Catal. A 2014, 390, 52-62.

29. Wu, Y. Y.; Mashayekhi, N. A.; Kung, H. H. Catal. Sci. Technol. 2013, 3, 2881-2891.

30. Cargnello, M.; Doan-Nguyen, V. V. T.; Gordon, T. R.; Diaz, R. E.; Stach, E. A.; Gorte, R. J.; Fornasiero, P.; Murray, C. B. Science 2013, 341, 771-773.

31. Rieck, J. S.; Bell, A. T. J. Catal. 1985, 96, 88-105.

32. van den Berg, F. G. A.; Glezer, J. H. E.; Sachtler, W. M. H. J. Catal. 1985, 93, 340-352.

33. Boffa, A. B.; Lin, C.; Bell, A. T.; Somorjai, G. A. Catal. Lett. 1994, 27, 243-249.

34. Nonneman, L. E. Y.; Ponec, V. Catal. Lett. 1990, 7, 197-204.

35. Sachtler, W. M. H.; Shriver, D. F.; Hollenberg, W. B.; Lang, A. F. J. Catal. 1985, 92, 429-431.

36. Johnson, G. R.; Werner, S.; Bell, A. T. AIChE Annu. Meet., Conf. Proc., Atlanta, GA, 2014; p paper $493 f$.

37. Johnson, G. R.; Werner, S.; Bell, A. T. Presented at the 24th Meeting of the North American Catalysis Society, Pittsburgh, PA, 2015.

38. Prieto, G.; De Mello, M. I. S.; Concepcíon, P.; Murciano, R.; Pergher, S. B. C.; Martínez, A. ACS Catal. 2015, 5, 3323-3335. 
39. Johnson, G. R.; Bell, A. T. ACS Catal. 2016, 6, 100-114.

40. Johnson, G. R.; Werner, S.; Bell, A. T. ACS Catal. 2015, 5, 5888-5902.

41. Reuel, R. C.; Bartholomew, C. H. J. Catal. 1984, 85, 63-77.

42. Kropf, A. J.; Katsoudas, J.; Chattopadhyay, S.; Shibata, T.; Lang, E. A.; Zyryanov, V. N.; Ravel, B.; Mclvor, K.; Kemner, K. M.; Scheckel, K. G.; Bare, S. R.; Terry, J.; Kelley, S. D.; Bunker, B. A.; Segre, C. U. AIP Conf. Proc., 2010; pp 299-302.

43. Ravel, B.; Newville, M. J. Synchrotron Radiat. 2005, 12, 537-541.

44. Newville, M. J. Synchrotron Radiat. 2001, 8, 96-100.

45. Cliff, G.; Lorimer, G. W. J. Microsc. 1975, 103, 203-207.

46. Weisz, P. B.; Prater, C. D. Adv. Catal. 1954, 6, 143-196.

47. Dinse, A.; Aigner, M.; Ulbrich, M.; Johnson, G. R.; Bell, A. T. J. Catal. 2012, 288, 104-114.

48. Khodakov, A. Y.; Lynch, J.; Bazin, D.; Rebours, B.; Zanier, N.; Moisson, B.; Chaumette, P. J. Catal. 1997, 168, 16-25.

49. Jacobs, G.; Ji, Y.; Davis, B. H.; Cronauer, D.; Kropf, A. J.; Marshall, C. L. Appl. Catal., A 2007, $333,177-191$.

50. Martínez, A.; López, C.; Márquez, F.; Díaz, I. J. Catal. 2003, 220, 486-499.

51. Girardon, J.-S.; Lermontov, A. S.; Gengembre, L.; Chernavskii, P. A.; Griboval-Constant, A.; Khodakov, A. Y. J. Catal. 2005, 230, 339-352.

52. Arnoldy, P.; Moulijn, J. A. J. Catal. 1985, 93, 38-54.

53. Stobbe, E. R.; de Boer, B. A.; Geus, J. W. Catal. Today 1999, 47, 161-167.

54. Laachir, A.; Perrichon, V.; Badri, A.; Lamotte, J.; Catherine, E.; Lavalley, J. C.; Fallah, J. E.; Hilaire, L.; Normand, F. L.; Quéméré, E.; Sauvion, G. N.; Touret, O. J. Chem. Soc., Faraday Trans. 1991, 87, 1601-1609.

55. Chen, M.; Hallstedt, B.; Gauckler, L. J. J. Phase Equilib. 2003, 24, 212-227.

56. Bezemer, G. L.; Bitter, J. H.; Kuipers, H. P. C. E.; Oosterbeek, H.; Holewijn, J. E.; Xu, X.; Kapteijn, F.; van Dillen, A. J.; de Jong, K. P. J. Am. Chem. Soc. 2006, 128, 3956-3964.

57. Melaet, G.; Lindeman, A. E.; Somorjai, G. A. Top. Catal. 2014, 57, 500-507.

58. Datye, A. K.; Xu, Q.; Kharas, K. C.; McCarty, J. M. Catal. Today 2006, 111, 59-67.

59. Pokrovski, K.; Jung, K. T.; Bell, A. T. Langmuir 2001, 17, 4297-4303.

60. Asakura, H.; Shishido, T.; Teramura, K.; Tanaka, T. Inorg. Chem. 2014, 53, 6048-6053. 
61. Bartholomew, C. H. Catal. Lett. 1990, 7, 27-52.

62. Williams, K. J.; Boffa, A. B.; Lahtinen, J.; Salmeron, M.; Bell, A. T.; Somorjai, G. A. Catal. Lett. 1990, 5, 385-394.

63. Yates, I. C.; Satterfield, C. N. Energ. Fuel 1991, 5, 168-173.

64. Ojeda, M.; Nabar, R.; Nilekar, A. U.; Ishikawa, A.; Mavrikakis, M.; Iglesia, E. J. Catal. 2010, 272, 287-297.

65. Zennaro, R.; Tagliabue, M.; Bartholomew, C. H. Catal. Today 2000, 58, 309-319.

66. Kung, H. H. Transition Metal Oxides: Surface Chemistry and Catalysis; Elsevier Science Publishing Company Inc.: New York, 1989.

67. Jeong, N. C.; Lee, J. S.; Tae, E. L.; Lee, Y. J.; Yoon, K. B. Angew. Chem. Int. Ed. 2008, 47, 10128-10132.

68. Sanderson, R. T. Chemical Bonds and Bond Energy; Academic Press: New York, 1976.

69. Prieto, G.; Concepción, P.; Martínez, A.; Mendoza, E. J. Catal. 2011, 280, 274-288.

70. Haddad, G. J.; Chen, B.; Goodwin, J. G., Jr. J. Catal. 1996, 160, 43-51.

71. Lavela, P.; Tirado, J. L.; Vidal-Abarca, C. Electrochim. Acta 2007, 52, 7986-7995.

72. Liang, Y.; Wang, H.; Zhou, J.; Li, Y.; Wang, J.; Regier, T.; Dai, H. J. Am. Chem. Soc. 2012, 134, 3517-3523.

73. Zavaliy, I. Y.; Denys, R. V.; Černý, R.; Koval'chuck, I. V.; Wiesinger, G.; Hilscher, G. J. Alloy Compd. 2005, 386, 26-34.

74. Faria, P. C. C.; Monteiro, D. C. M.; Órfão, J. J. M.; Pereira, M. F. R. Chemosphere 2009, 74, 818-824.

75. Ito, T.; Zhang, Q.; Saito, F. Powder Technol. 2004, 143-144, 170-173.

76. Ivas, T. Cerium-Gadolinium-Cobalt-Oxides: Phase Equilibria and Defect Chemistry in Bulk and Grain Boundaries; PhD Thesis; ETH Zurich: Zürich, Switzerland, 2013.

77. Sachtler, W. M.; Ichikawa, M. J. Phys. Chem. 1986, 90, 4752-4758.

78. Horwitz, C. P.; Shriver, D. F. Adv. Organomet. Chem. 1984, 23, 219-305.

79. Barrault, J.; Guilleminot, A. Appl. Catal. 1986, 21, 307-312.

80. den Breejen, J. P.; Radstake, P. B.; Bezemer, G. L.; Bitter, J. H.; Frøseth, V.; Holmen, A.; de Jong, K. P. J. Am. Chem. Soc. 2009, 131, 7197-7203.

81. Ishihara, T.; Eguchi, K.; Arai, H. J. Molec. Catal. 1992, 72, 253-261. 
Table 1. Physical properties of the metal oxide-promoted catalysts.

\begin{tabular}{cccccc}
\hline $\begin{array}{c}\text { Promoter } \\
\text { Element }\end{array}$ & $\begin{array}{c}\text { Promoter/Co } \\
\text { Atomic Ratio }^{a}\end{array}$ & $\begin{array}{c}\text { Co Loading }^{b} \\
(\mathrm{wt} \%)\end{array}$ & $\begin{array}{c}\mathrm{d}(\mathrm{Co})^{c} \\
(\mathrm{~nm})\end{array}$ & $\begin{array}{c}\mathrm{O}_{2} \text { Uptake } \\
\left(\mathrm{mmol} \mathrm{g}_{\text {cat }^{-1}}\right)\end{array}$ & $\begin{array}{c}\mathrm{H}_{2} \text { Uptake } \\
\left(\mathrm{mmol} \mathrm{gat}^{-1}\right)\end{array}$ \\
\hline Unpromoted & N/A & 9.8 & $12 \pm 3$ & 0.97 & 0.059 \\
La & 0.1 & 8.9 & $12 \pm 4$ & 0.80 & 0.040 \\
$\mathrm{Ce}$ & 2.0 & 6.4 & $9 \pm 2$ & 1.1 & 0.088 \\
$\mathrm{Mn}$ & 0.1 & 9.4 & $11 \pm 3$ & 0.82 & 0.022 \\
$\mathrm{Gd}$ & 1.0 & 7.3 & $10 \pm 3$ & 0.53 & 0.067 \\
$\mathrm{Zr}$ & 1.0 & 7.7 & $10 \pm 4$ & 0.55 & 0.017 \\
\hline
\end{tabular}

${ }^{a}$ Composition at which selectivity becomes insensitive to promoter loading.

${ }^{b}$ Compositions were determined by ICP-OES.

${ }^{c}$ Surface mean diameter of Co metal nanoparticles. 
Table 2. Extent of Co reduction, nanoparticle dispersion, and promoter coverage of the nanoparticle surfaces.

\begin{tabular}{|c|c|c|c|c|}
\hline $\begin{array}{c}\text { Promoter } \\
\text { Element }\end{array}$ & $\begin{array}{l}\text { Promoter/Co } \\
\text { Atomic Ratio }^{a}\end{array}$ & $\begin{array}{c}\mathrm{Co}(0)^{b} \\
(\%)\end{array}$ & $\begin{array}{c}\text { Dispersion }^{c} \\
(\%)\end{array}$ & $\begin{array}{c}\text { Promoter Coverage } \\
(\%)\end{array}$ \\
\hline Unpromoted & $\mathrm{N} / \mathrm{A}$ & 83 & 8.3 & $\mathrm{~N} / \mathrm{A}$ \\
\hline La & 0.1 & 73 & 8.2 & $10 \pm 20$ \\
\hline $\mathrm{Ce}$ & 2.0 & 69 & 11 & - \\
\hline $\mathrm{Mn}$ & 0.1 & 59 & 8.7 & $50 \pm 20$ \\
\hline $\mathrm{Gd}$ & 1.0 & 52 & 9.7 & - \\
\hline $\mathrm{Zr}$ & 1.0 & 52 & 9.2 & $40 \pm 30$ \\
\hline
\end{tabular}

${ }^{a}$ Composition at which selectivity becomes insensitive to promoter loading.

${ }^{b}$ Percentage of $\mathrm{Co}$ in the metallic state after reduction.

${ }^{c}$ Determined by particle sizes assuming a site density of 14.6 Co atoms $/ \mathrm{nm}^{2}$.

${ }^{d}$ Percentage of the metallic Co nanoparticle surface area covered by the promoter. 
Table 3. Rate parameters for unpromoted and metal oxide-promoted $\mathrm{Co} / \mathrm{SiO}_{2}(\mathrm{~T}=493 \mathrm{~K})$.

\begin{tabular}{ccccc}
\hline Promoter Oxide & $\begin{array}{c}\text { Promoter/Co } \\
\text { Atomic Ratio }\end{array}$ & $\begin{array}{c}\text { Rel. Lewis Acidity } \\
\left(N_{M}-2 \delta_{M}\right)\end{array}$ & $\begin{array}{c}a^{b} \\
\left(\text { bar }^{-1} \mathrm{~s}^{-1}\right)\end{array}$ & $\begin{array}{c}b \\
\left(\text { bar }^{-1}\right)\end{array}$ \\
\hline Unpromoted & N/A & 0 & 0.085 & 1.4 \\
$\mathrm{La}_{2} \mathrm{O}_{3}$ & 0.1 & 0.85 & 0.14 & 2.9 \\
$\mathrm{Ce}_{2} \mathrm{O}_{3}$ & 2.0 & 0.96 & 0.13 & 3.1 \\
$\mathrm{MnO}$ & 0.1 & 1.4 & 0.26 & 3.3 \\
$\mathrm{Gd}_{2} \mathrm{O}_{3}$ & 1.0 & 1.4 & 0.32 & 3.8 \\
$\mathrm{ZrO}_{4}$ & 1.0 & 2.5 & 0.32 & 5.0 \\
\hline
\end{tabular}

${ }^{a}$ Composition at which selectivity becomes insensitive to promoter loading.

${ }^{b}$ Assuming that the Co nanoparticle surface is covered by a half monolayer of the promoter. 


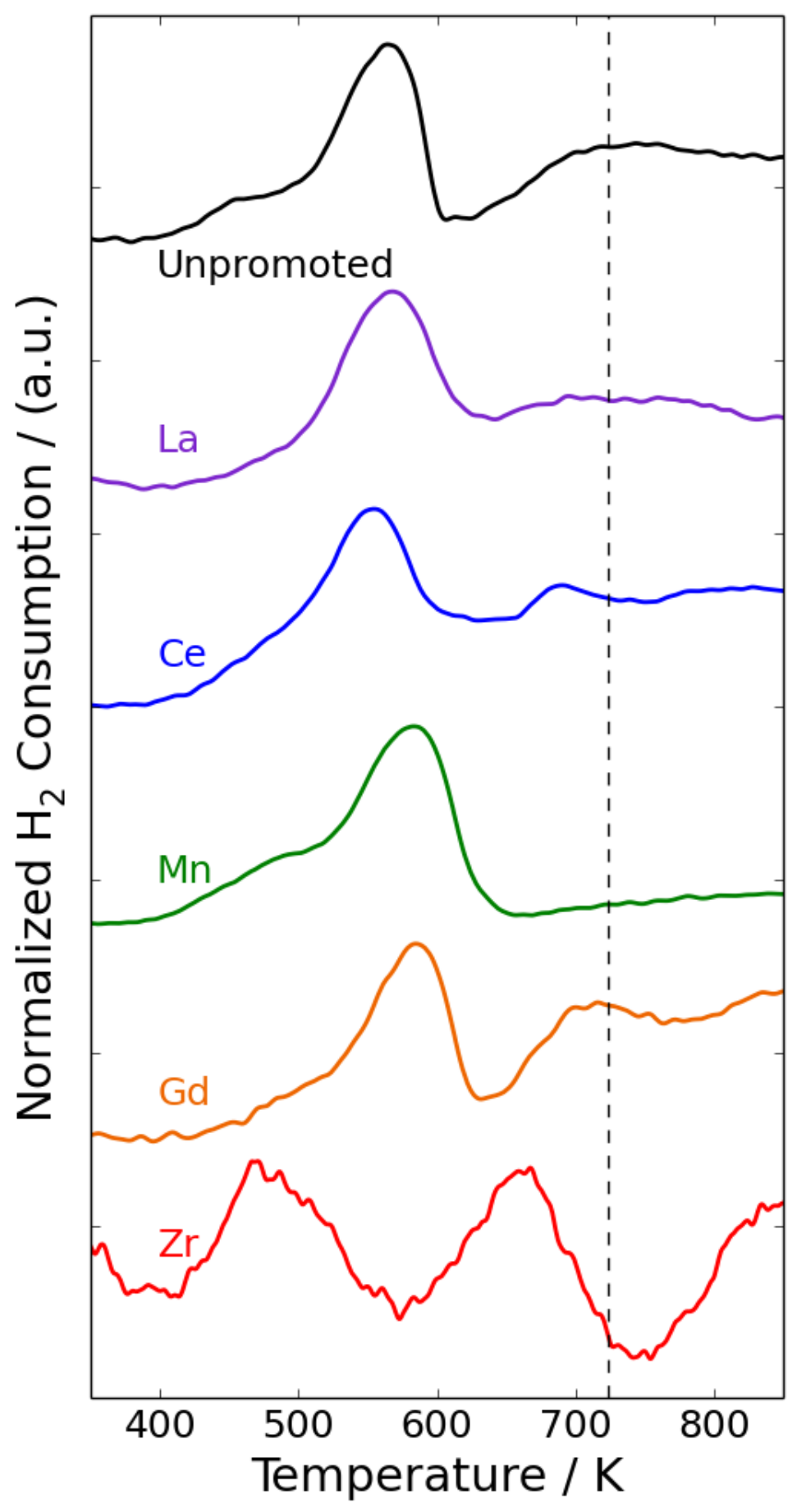

Figure 1. TPR profiles of unpromoted and metal oxide-promoted catalysts. The samples were heated at $5 \mathrm{~K} / \mathrm{min}$ from 298 to $873 \mathrm{~K}$ in a carrier gas composed of $1 \% \mathrm{H}_{2}, 1 \% \mathrm{Ar}, 98 \% \mathrm{He}$. The vertical dashed line at $723 \mathrm{~K}$ indicates the temperature at which the catalysts were reduced prior to conducting FTS reactions. 


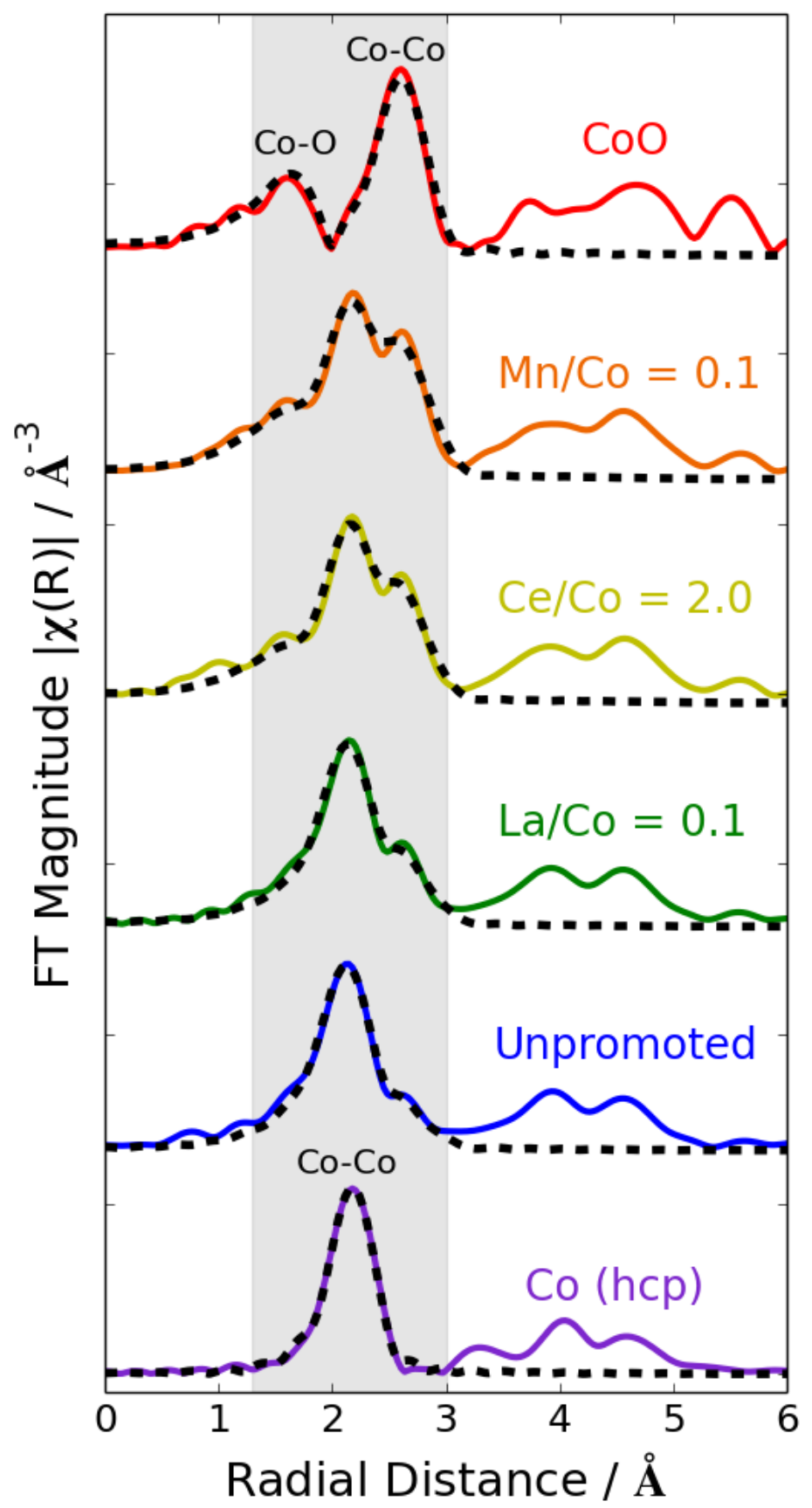

Figure 2. Co K-edge EXAFS spectra of unpromoted and metal oxide-promoted $\mathrm{Co} / \mathrm{SiO}_{2}$. Catalysts were reduced under flowing $\mathrm{H}_{2}$ at $723 \mathrm{~K}$ for $2 \mathrm{~h}$ prior to collecting the spectra at ambient temperature and pressure under $\mathrm{He}$. The $\mathrm{Co}$ metal and $\mathrm{CoO}$ references were measured without pretreatment. The solid colored lines in the plots are the $\mathrm{k}^{2}$-weighted Fourier transforms of the EXAFS spectra, and the dashed black lines are fits to these data within the shaded gray region. 
A)

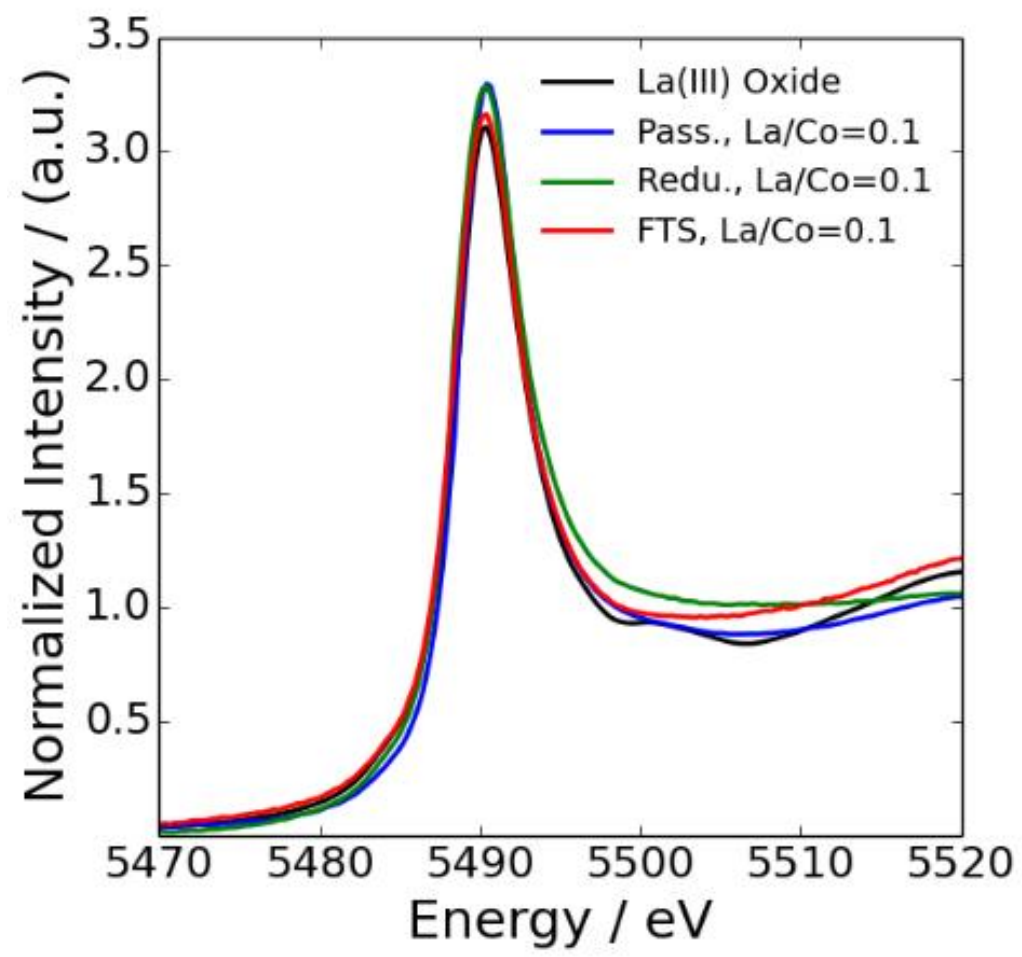

B)

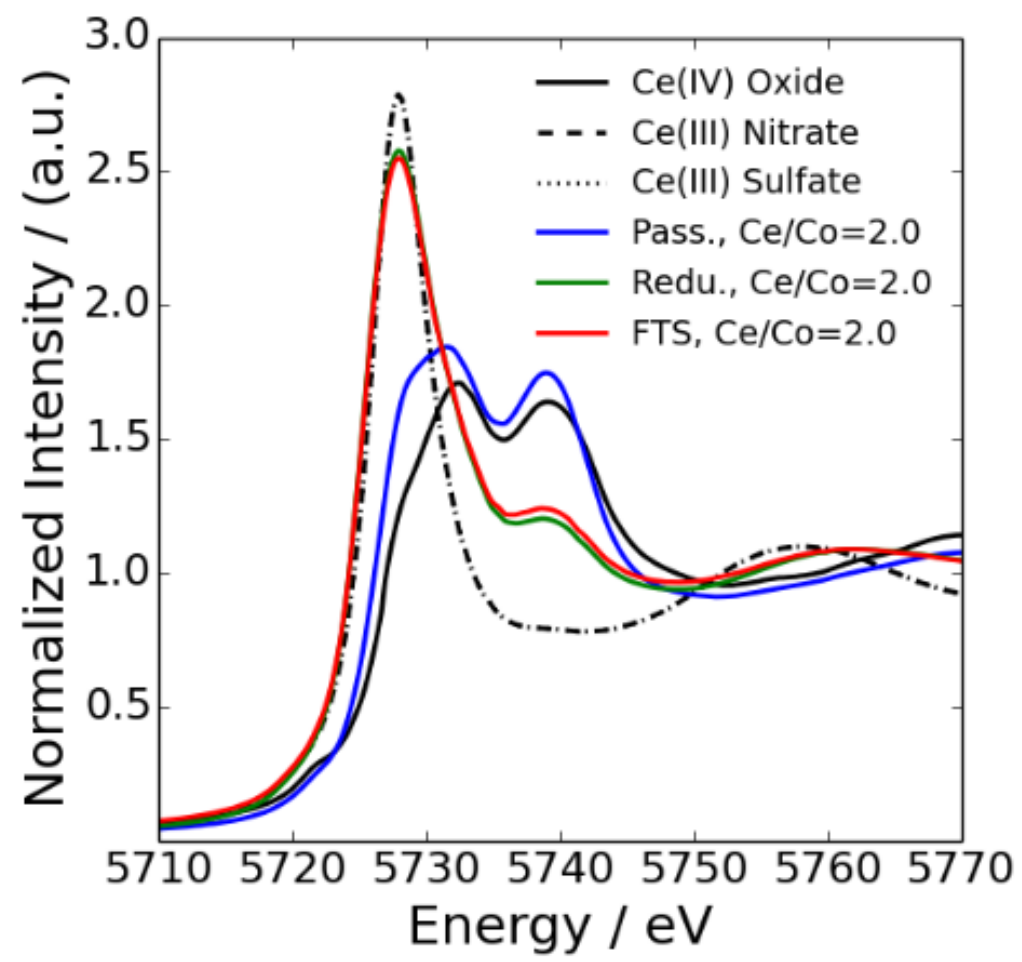


C)

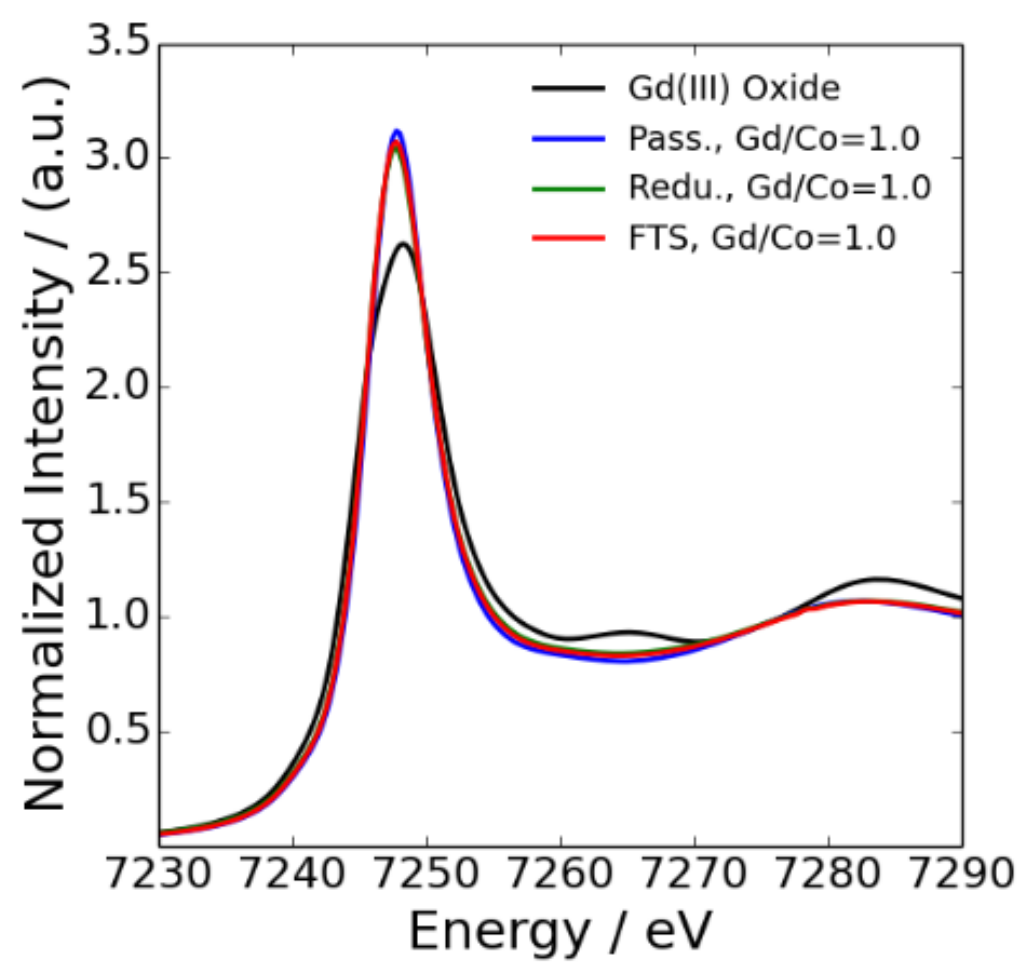

Figure 3. In situ XANES spectra of the catalysts prepared with (A) La/Co $=0.1,(B) \mathrm{Ce} / \mathrm{Co}=2.0$, and $(C) \mathrm{Gd} / \mathrm{Co}=1.0$. The spectra were collected at the $\mathrm{L}_{3}$-edges for the promoter element at three conditions: passivated at ambient temperature (Pass.), after reduction with $\mathrm{H}_{2}$ at $723 \mathrm{~K}$ for $2 \mathrm{~h}$ and cooling to $493 \mathrm{~K}$ (Redu.), and under $2 / 1 \mathrm{H}_{2} / \mathrm{CO}$ synthesis gas at $493 \mathrm{~K}$ (FTS). 
A)
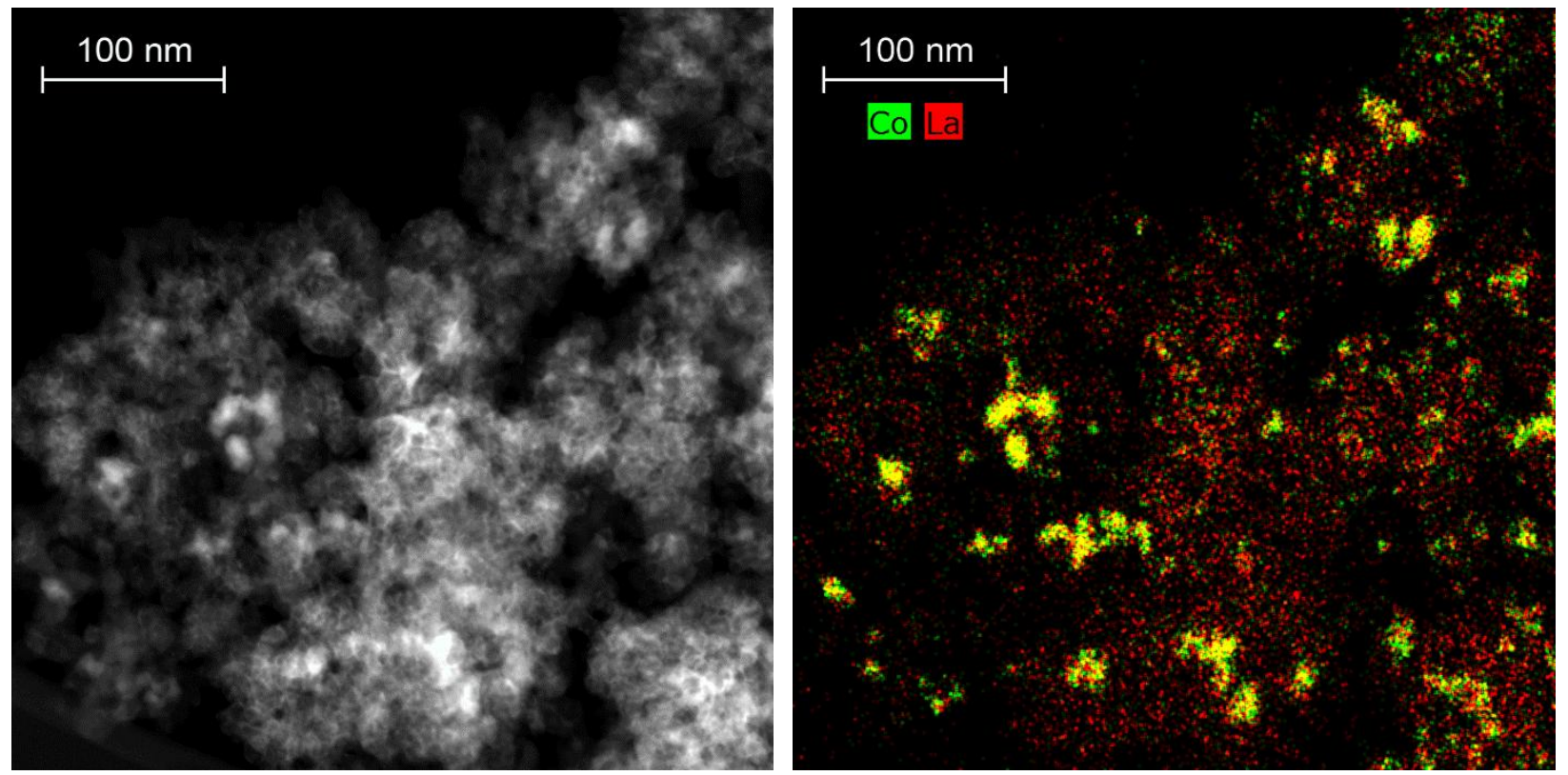

B)
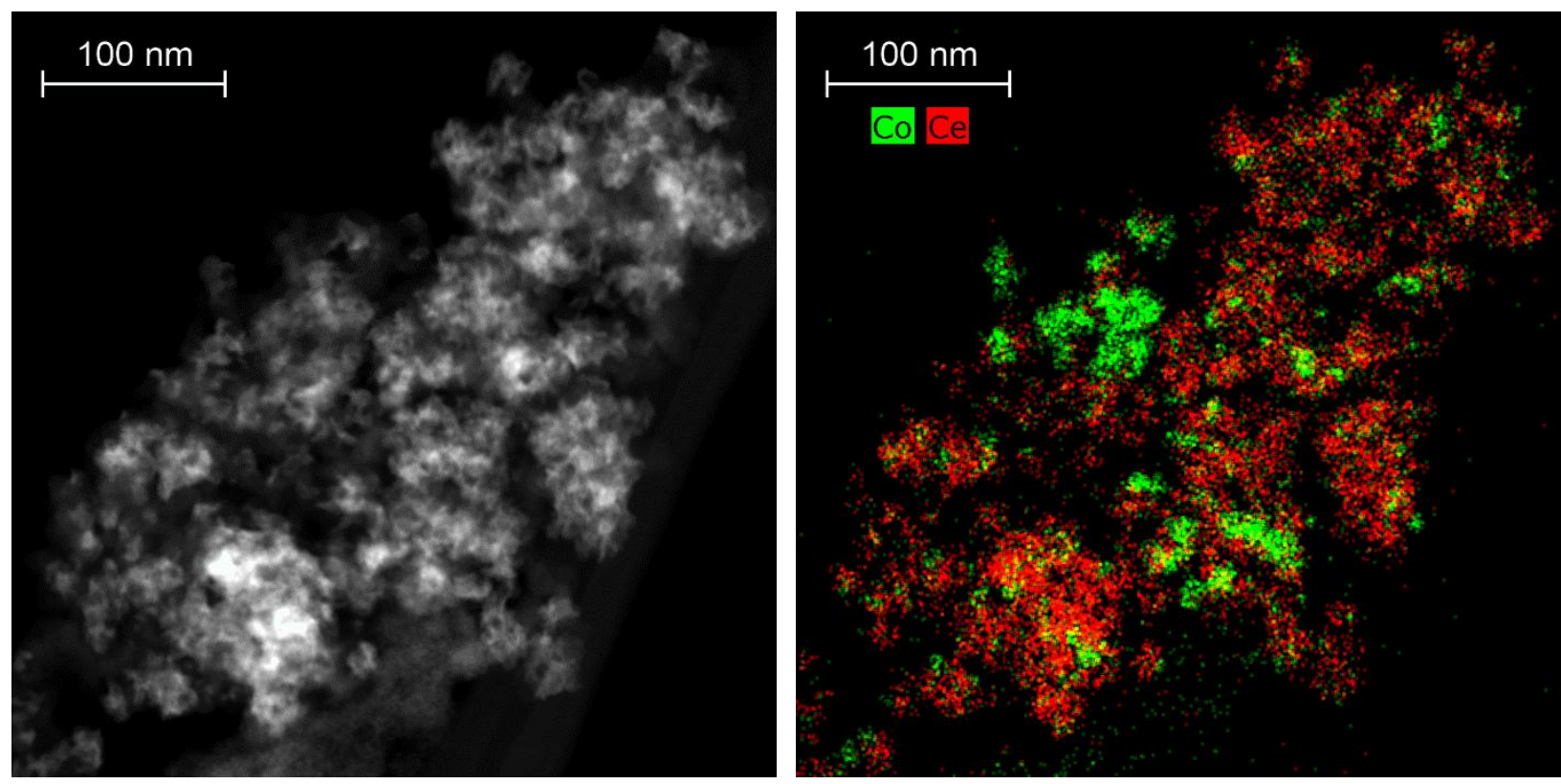
C)
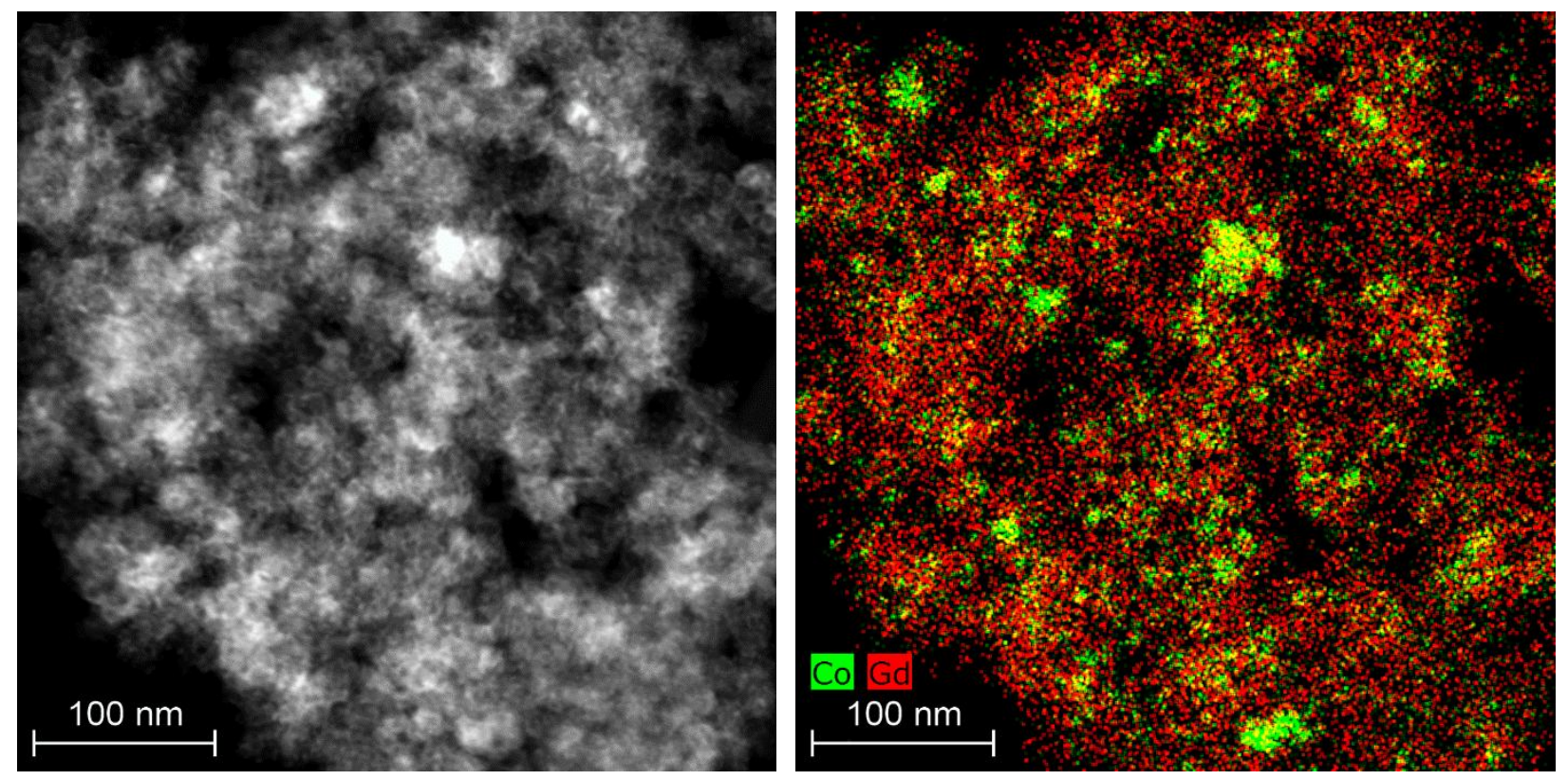

Figure 4. Representative HAADF-STEM images and STEM-EDS elemental maps for catalysts prepared with (A) $\mathrm{La} / \mathrm{Co}=0.1,(\mathrm{~B}) \mathrm{Ce} / \mathrm{Co}=2.0$, and (C) $\mathrm{Gd} / \mathrm{Co}=1.0$. In each elemental map, the Co and promoter signals are normalized separately to the pixels with the highest $\mathrm{Co}$ and promoter X-ray counts, respectively. 
A)
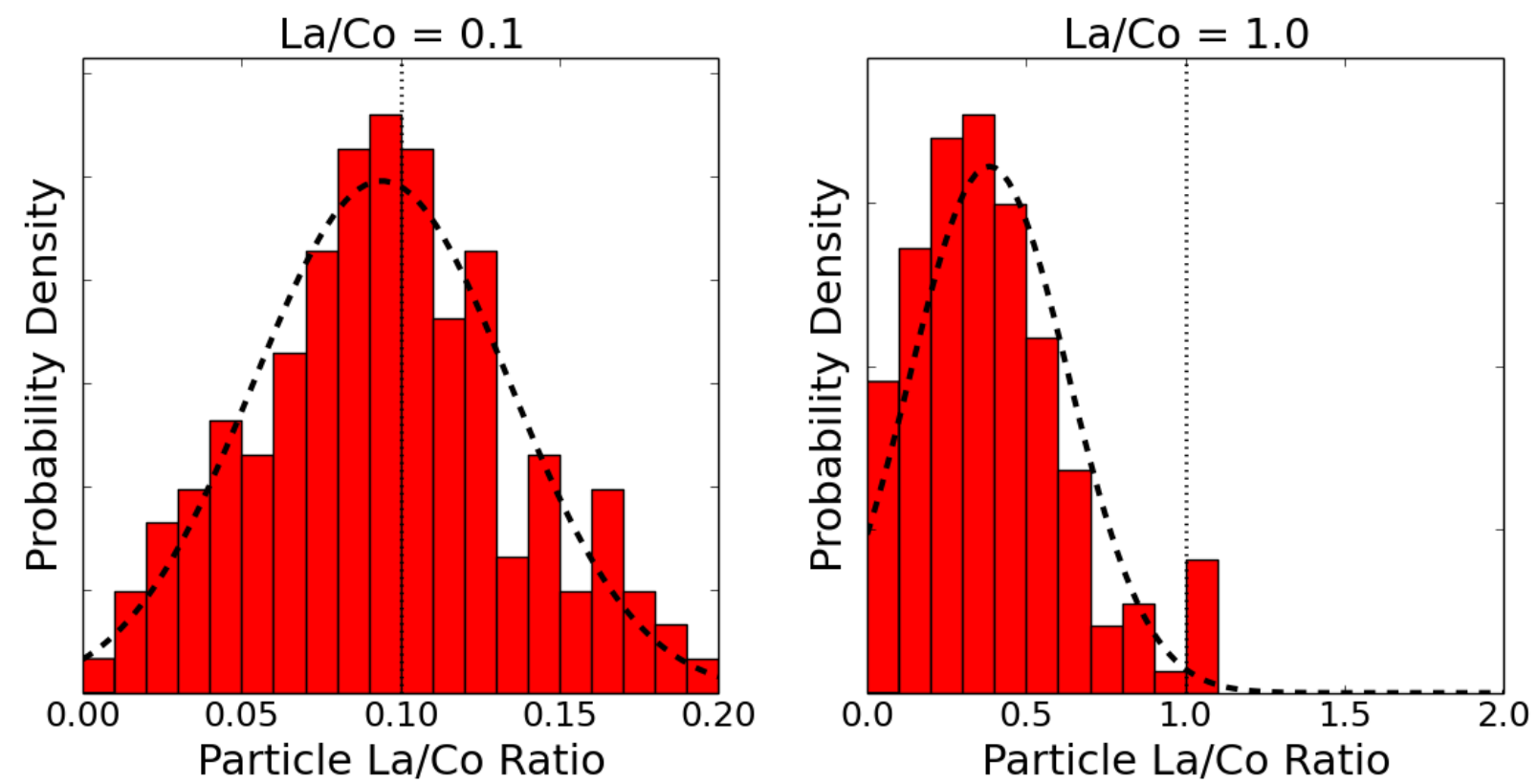

B)
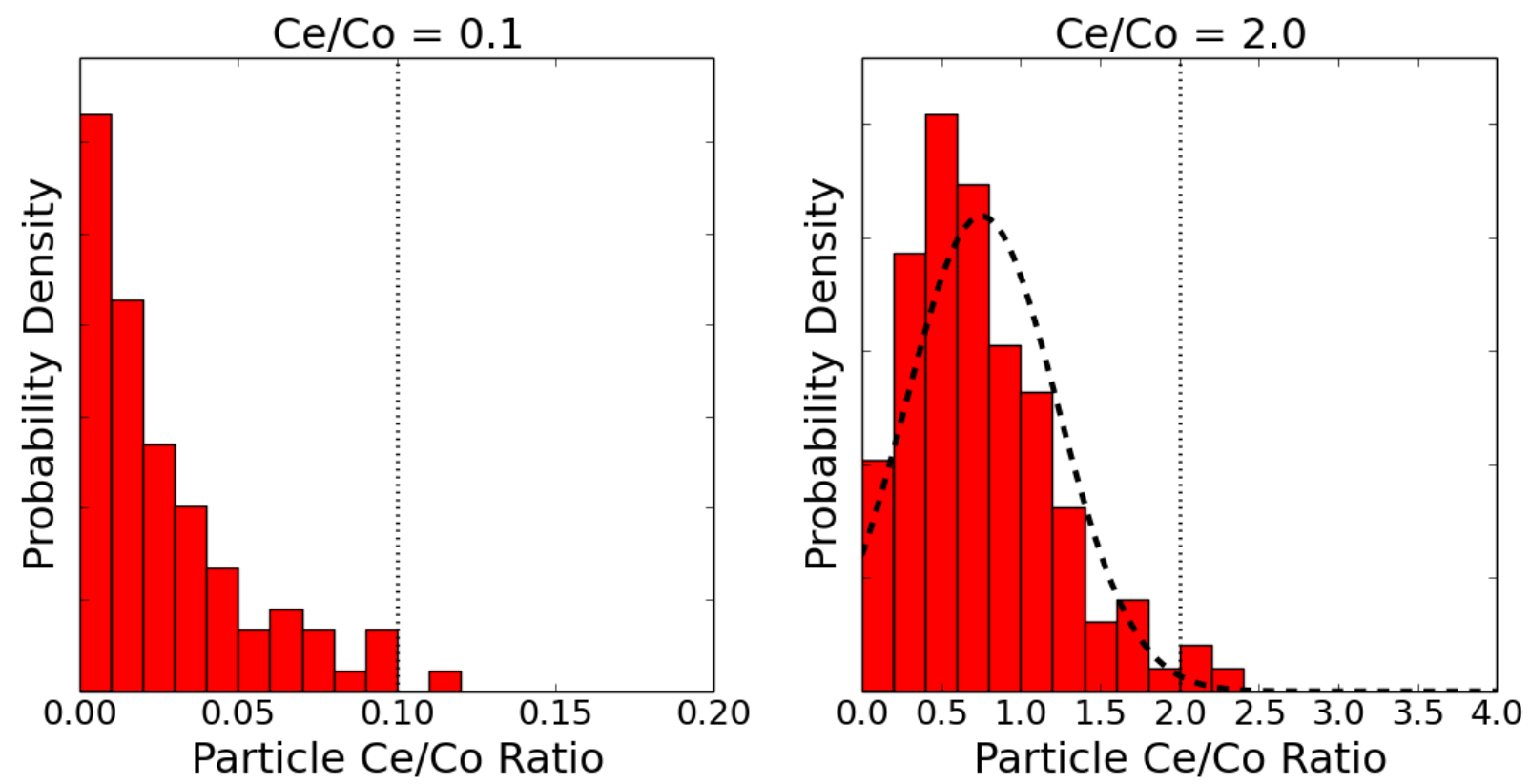
C)
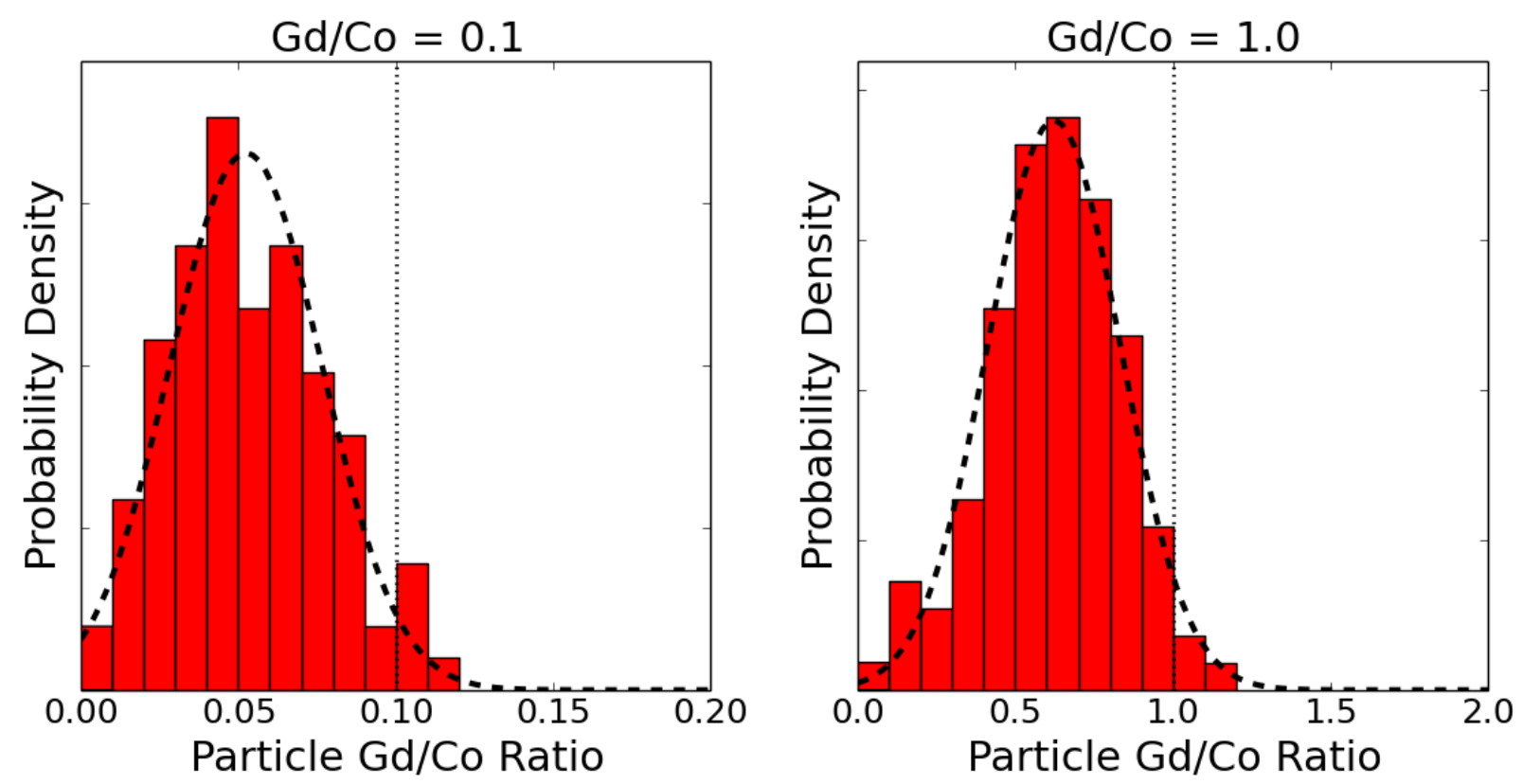

Figure 5. Nanoparticle composition histograms for catalysts prepared with (A) La, (B) Ce, and (C) Gd promoters with promoter/Co ratios of (first column) 0.1 and (second column) 1.0. The dashed curves in the histograms are Gaussian functions fitted to the data. The dotted vertical lines indicate the bulk catalyst compositions. 


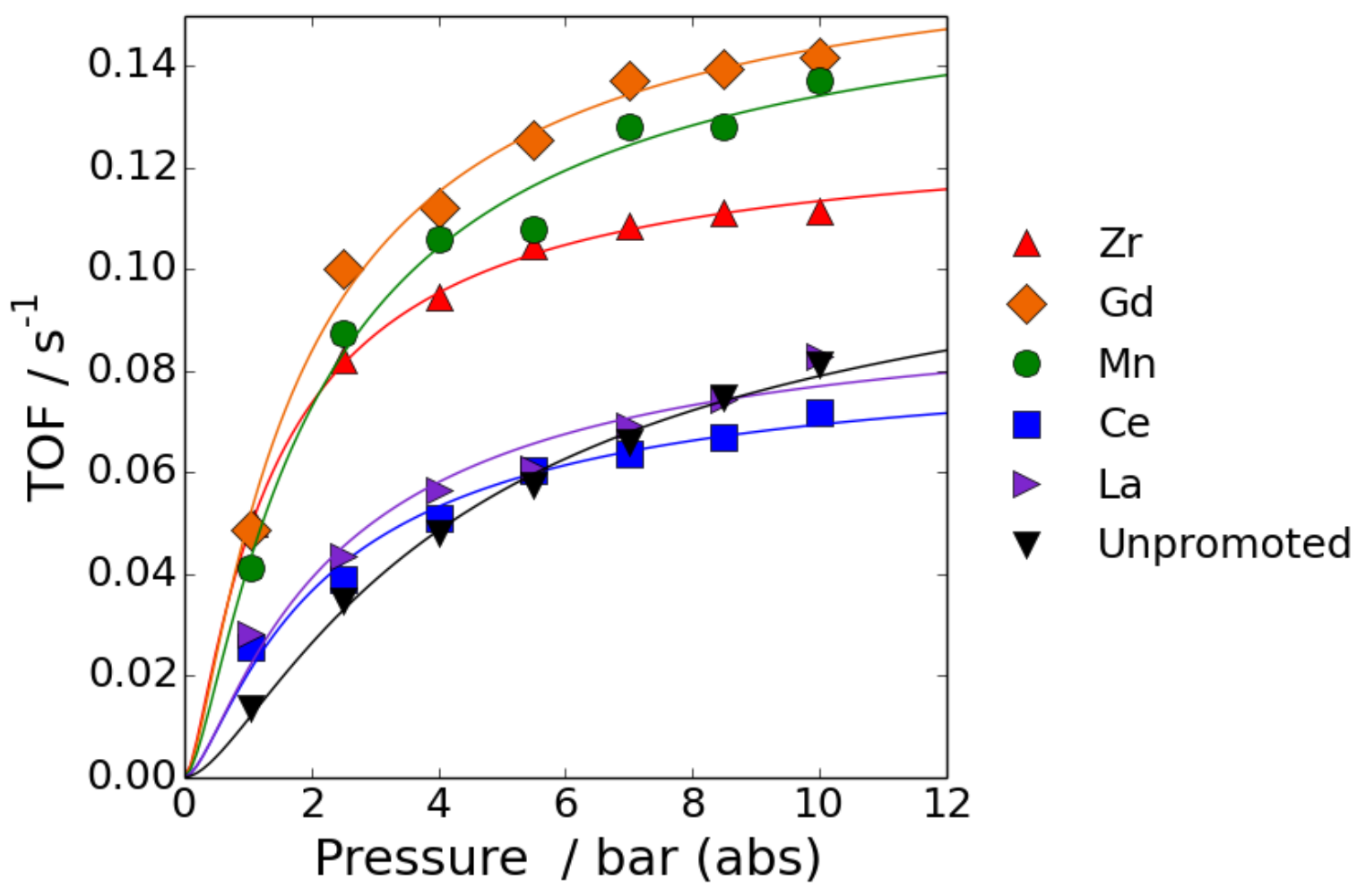

Figure 6. FTS turnover frequencies as a function of pressure for unpromoted and metal oxidepromoted $\mathrm{Co} / \mathrm{SiO}_{2}$. The catalyst compositions correspond to those in Table 1 ( $\mathrm{La} / \mathrm{Co}=0.1$; $\mathrm{Ce} / \mathrm{Co}=2.0 ; \mathrm{Mn} / \mathrm{Co}=0.1 ; \mathrm{Gd} / \mathrm{Co}=1.0 ; \mathrm{Zr} / \mathrm{Co}=1.0$ ). For each catalyst, it was assumed that the Co nanoparticles were covered by a half monolayer of the promoter. The data were collected at $493 \mathrm{~K}$ with a reactor feed of $7 \% \mathrm{Ar}, 31 \% \mathrm{CO}$, and $62 \% \mathrm{H}_{2}(50-150 \mathrm{~mL} / \mathrm{min})$. All datapoints were extrapolated to $0 \% \mathrm{CO}$ conversion. The curves in each plot are fits to the data using the rate law given by eq. 2 . 
A)

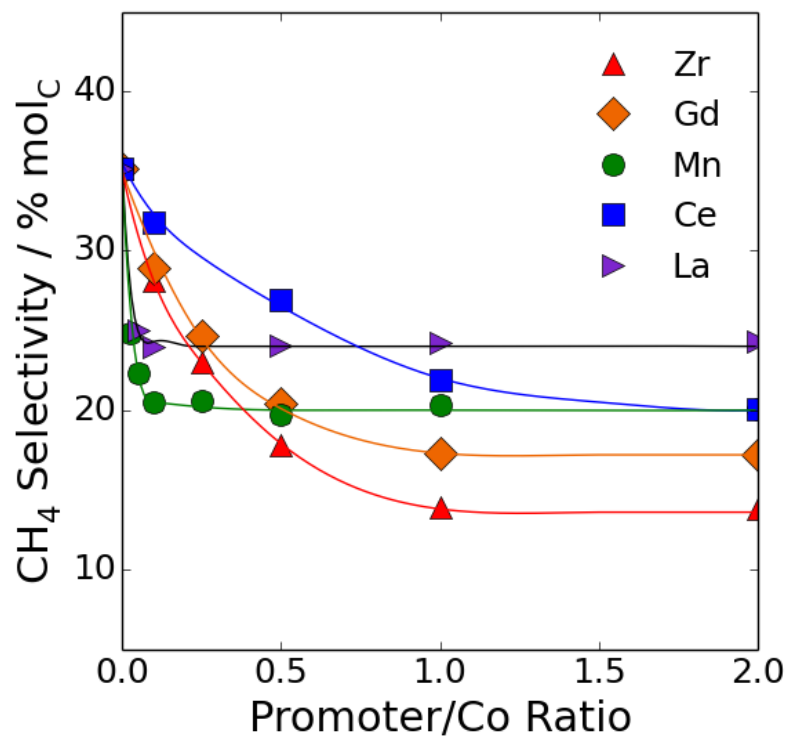

B)

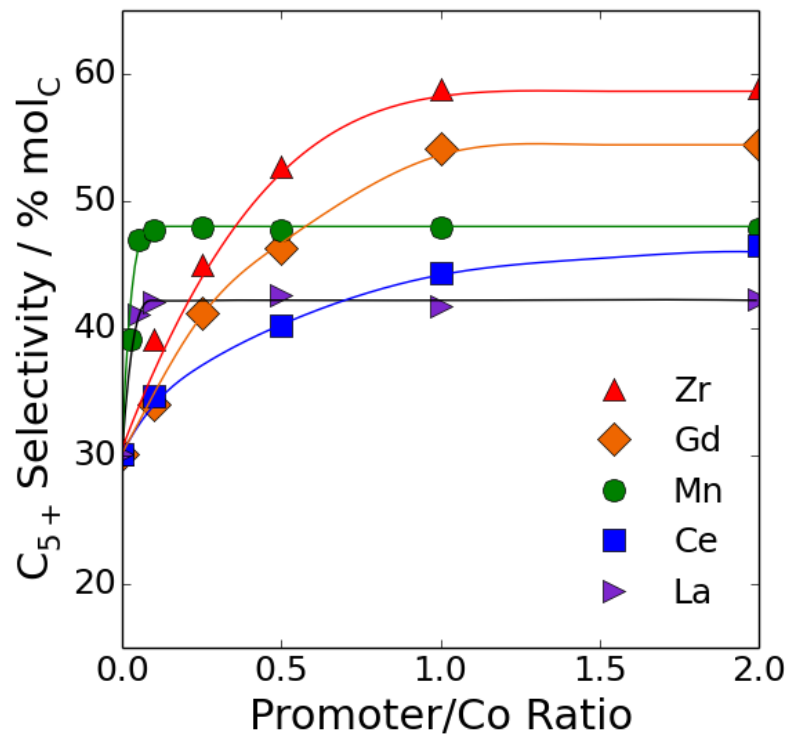

Figure 7. Effects of promoter loading on the selectivity toward $(A) \mathrm{CH}_{4}$ and $(B) \mathrm{C}_{5+}$ hydrocarbons measured at $493 \mathrm{~K}$ and 1 bar. The data were collected with a reactor feed of $7 \%$ Ar, $31 \% \mathrm{CO}$, and $62 \% \mathrm{H}_{2}(50-150 \mathrm{~mL} / \mathrm{min})$. All data points were extrapolated to $0 \% \mathrm{CO}$ conversion. The curves in each plot are cubic splines included as a visual aid. 
A)

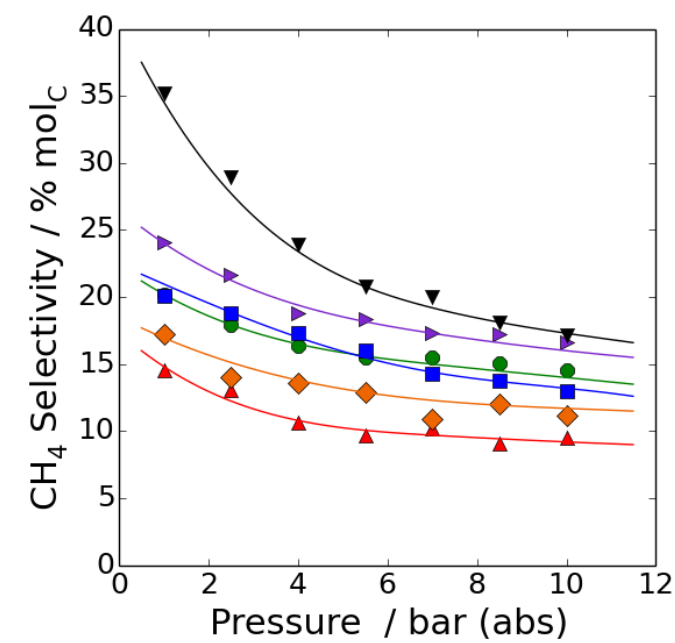

B)

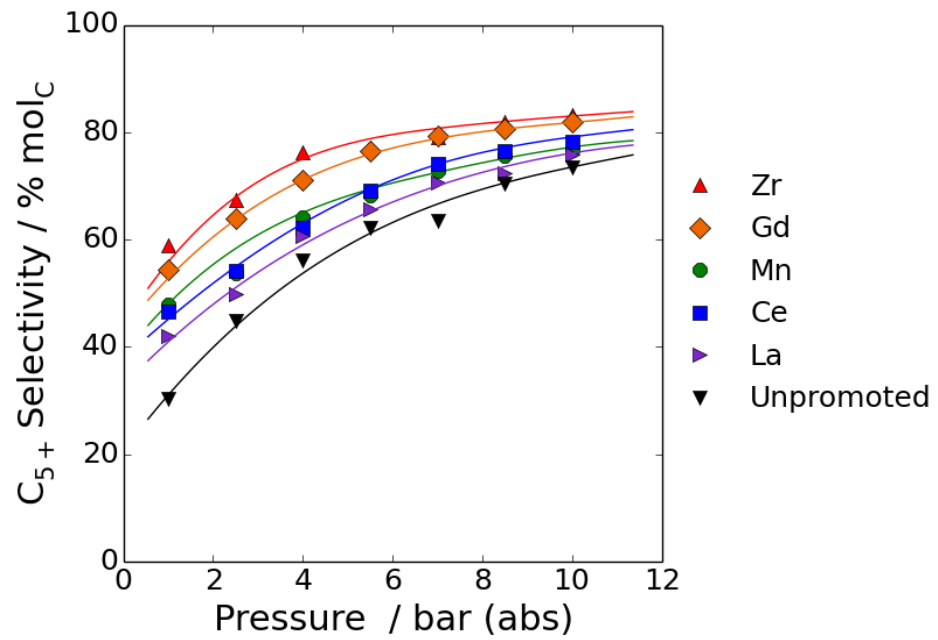

Figure 8. Selectivities toward (A) $\mathrm{CH}_{4}$ and (B) $\mathrm{C}_{5_{+}}$hydrocarbons as a function of pressure for unpromoted and metal oxide-promoted $\mathrm{Co} / \mathrm{SiO}_{2}$. All data were collected at $493 \mathrm{~K}$ with a reactor feed of $7 \% \mathrm{Ar}, 31 \% \mathrm{CO}$, and $62 \% \mathrm{H}_{2}(50-150 \mathrm{~mL} / \mathrm{min})$. The data points in the figure were extrapolated to $0 \% \mathrm{CO}$ conversion. The catalyst compositions correspond to those in Table 1 $(\mathrm{La} / \mathrm{Co}=0.1 ; \mathrm{Ce} / \mathrm{Co}=2.0 ; \mathrm{Mn} / \mathrm{Co}=0.1 ; \mathrm{Gd} / \mathrm{Co}=1.0 ; \mathrm{Zr} / \mathrm{Co}=1.0)$. The curves in each plot are cubic splines included as a visual aid. 
B)
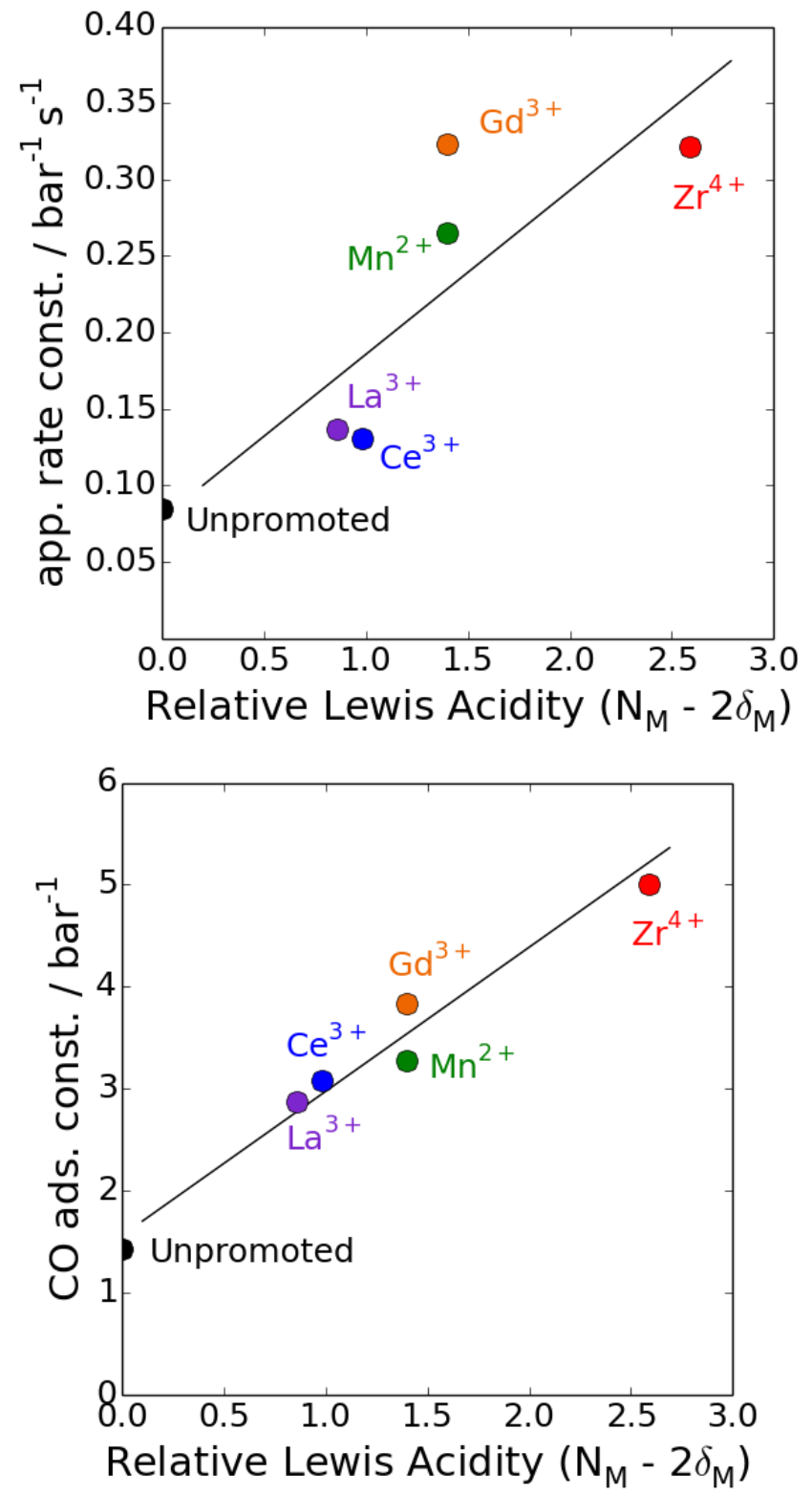

Figure 9. Correlation of $(A)$ the apparent rate coefficient and $(B)$ the $\mathrm{CO}$ adsorption constant with the relative Lewis acidity of the promoter oxide, represented by $N_{M}-2 \delta_{M}$ (see text). The apparent rate coefficient and CO adsorption constant correspond to parameters $a$ and $b$ in eq. 2 , respectively. The turnover frequency data presented in Figure 6 were used to determine these parameters. The CO consumption rate data used for the fits were collected at $493 \mathrm{~K}$ at 
pressures between 0 and 10 bar with a reactor feed of $7 \% \mathrm{Ar}, 31 \% \mathrm{CO}$, and $62 \% \mathrm{H}_{2}$ (50-150 $\mathrm{mL} / \mathrm{min}$ ) and were extrapolated to $0 \% \mathrm{CO}$ conversion. 


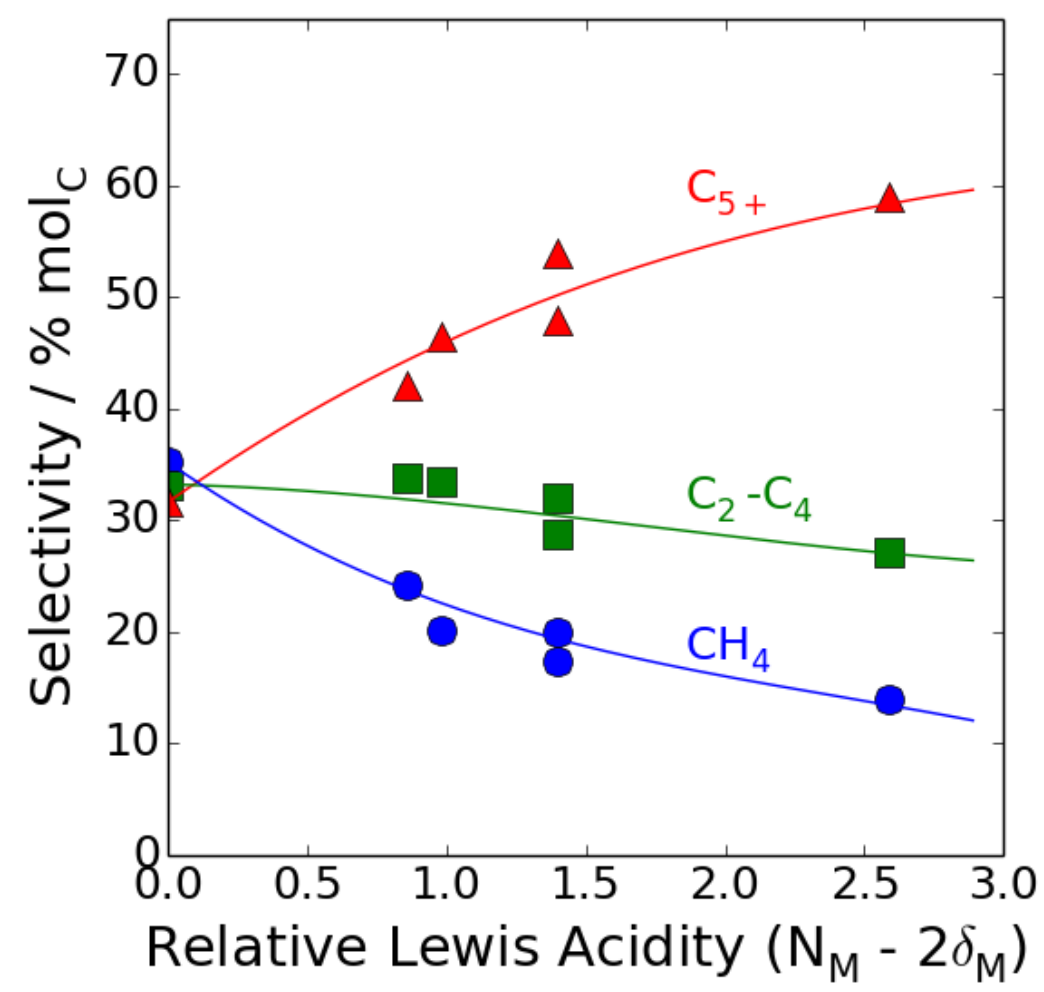

Figure 10. Selectivities toward $\mathrm{CH}_{4}, \mathrm{C}_{2}-\mathrm{C}_{4}$, and $\mathrm{C}_{5+}$ as a function of the promoter Lewis acidity. Here, $N_{M}-2 \delta_{M}$ is used as a proxy for the relative Lewis acidity of the promoter oxide, and the unpromoted catalyst was assigned a value of 0 . An index of these values for each promoter is provided in Table 3. The selectivities correspond to those Figure 7 where the promoter loading was high enough such that the product selectivities were insensitive to promoter loading. The data were collected at $493 \mathrm{~K}$ at atmospheric pressure with a feed composition of $7 \% \mathrm{Ar}, 31 \%$ $\mathrm{CO}$, and $62 \% \mathrm{H}_{2}(50-150 \mathrm{~mL} / \mathrm{min})$ and were extrapolated to $0 \% \mathrm{CO}$ conversion. 